\title{
Biological perspectives and current biofabrication strategies in osteochondral tissue engineering
}

\author{
Cian Vyas $^{1} \odot \cdot$ Hussein Mishbak $^{1,2} \cdot$ Glen $^{1}$ Cooper $^{1} \cdot$ Chris Peach $^{1,3} \cdot$ Ruben F. Pereira $^{4,5} \cdot$ Paulo Bartolo $^{1}$
}

Received: 26 September 2019 / Accepted: 29 June 2020 / Published online: 9 July 2020

(c) The Author(s) 2020

\begin{abstract}
Articular cartilage and the underlying subchondral bone are crucial in human movement and when damaged through disease or trauma impacts severely on quality of life. Cartilage has a limited regenerative capacity due to its avascular composition and current therapeutic interventions have limited efficacy. With a rapidly ageing population globally, the numbers of patients requiring therapy for osteochondral disorders is rising, leading to increasing pressures on healthcare systems. Research into novel therapies using tissue engineering has become a priority. However, rational design of biomimetic and clinically effective tissue constructs requires basic understanding of osteochondral biological composition, structure, and mechanical properties. Furthermore, consideration of material design, scaffold architecture, and biofabrication strategies, is needed to assist in the development of tissue engineering therapies enabling successful translation into the clinical arena. This review provides a starting point for any researcher investigating tissue engineering for osteochondral applications. An overview of biological properties of osteochondral tissue, current clinical practices, the role of tissue engineering and biofabrication, and key challenges associated with new treatments is provided. Developing precisely engineered tissue constructs with mechanical and phenotypic stability is the goal. Future work should focus on multi-stimulatory environments, long-term studies to determine phenotypic alterations and tissue formation, and the development of novel bioreactor systems that can more accurately resemble the in vivo environment.
\end{abstract}

Keywords Articular cartilage $\cdot$ Osteochondral tissue $\cdot$ Tissue engineering $\cdot$ Biofabrication $\cdot$ Bioprinting $\cdot 3 \mathrm{D}$ printing . Regenerative medicine

\section{Introduction}

Osteochondral tissue is composed of articular cartilage, a specialised tissue that covers the distal ends of the bones in articulating joints, and the subchondral bone which anchors the cartilage to the underlying bone [1-5]. Articular cartilage

Cian Vyas

cian.vyas@manchester.ac.uk

1 Department of Mechanical, Aerospace and Civil Engineering, University of Manchester, Manchester, UK

2 School of Engineering, University of Thi-Qar, Thi-Qar, Iraq

3 Consultant Orthopaedic and Trauma Surgeon, Manchester University Foundation NHS Trust, Manchester, UK

4 i3S - Instituto de Investigação e Inovação em Saúde, Universidade do Porto, Porto, Portugal

5 INEB - Instituto Nacional de Engenharia Biomédica, Universidade do Porto, Porto, Portugal has a highly flexible and lubricated surface to reduce frictional forces during movement and facilitate smooth articulation. The tissue enables the transmission of mechanical loads from movement to the skeleton [6-9]. Osteochondral tissue is composed of distinct regions with articular cartilage, comprising the majority of the structure, and an underlying subchondral bone phase.

Articular cartilage is avascular and aneural with low metabolic activity and thus when trauma or disease (e.g. osteoarthritis and rheumatoid arthritis) affects the tissue significant issues arise, which are difficult to treat due to the inherent inability of articular cartilage to self-regenerate in comparison to the greater healing capacity of bone (Fig. 1). As an avascular tissue, cartilage lacks ready access to a supply of circulating stem cells and nutrients thus relies on the synovial fluid for nourishment. This combined with its largely acellular composition and low metabolic activity results in a nearly complete lack of innate regenerative capacity. Consequentially, defects due to disease and trauma 


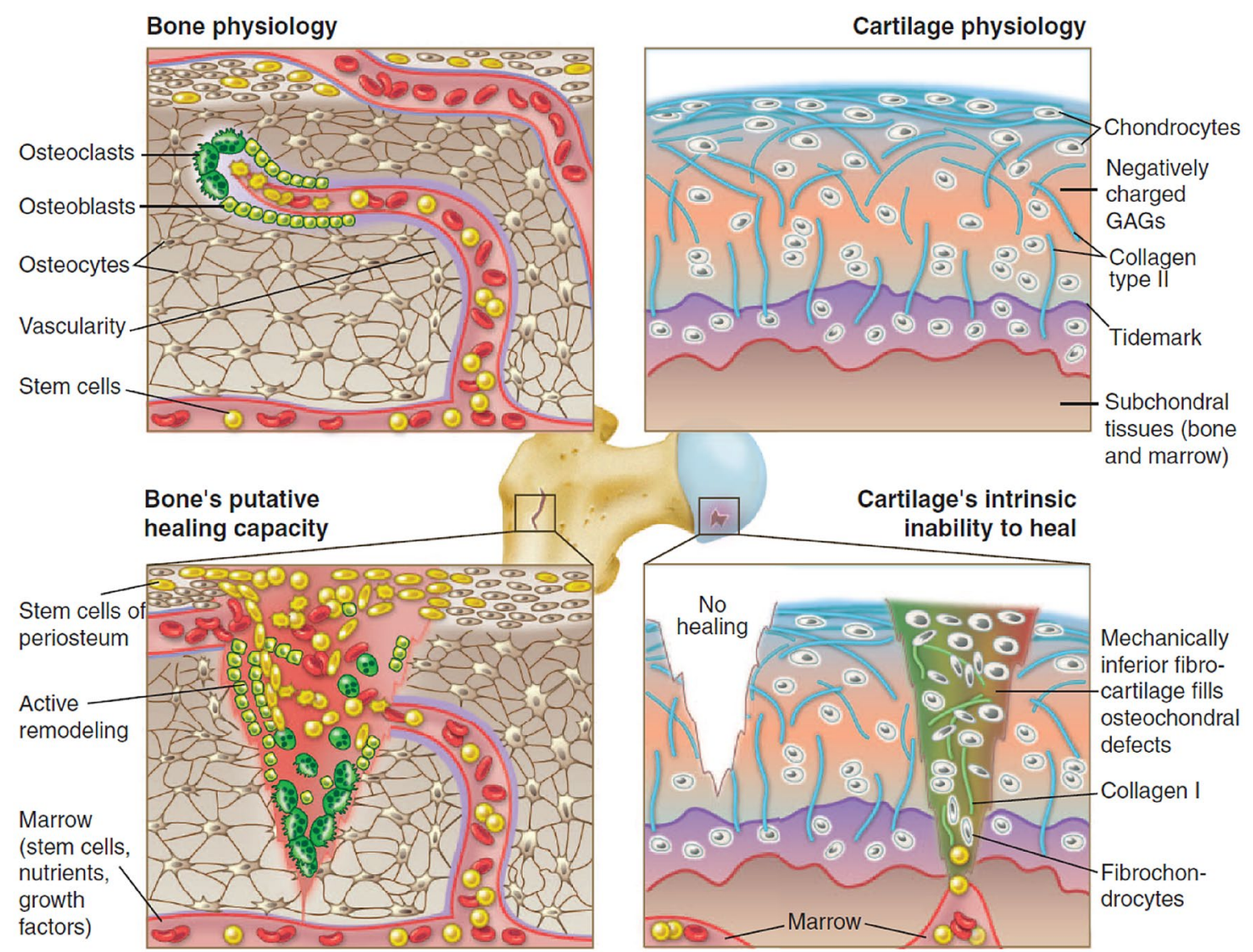

Fig. 1 Comparison between the physiology and healing capacity of bone and cartilage. Image from [9]

fail to heal, and clinical interventions typically result in the formation of fibrocartilage which has reduced functionality. In contrast, bone has a greater ability for self-repair due to constant tissue remodelling by the dynamic interplay between osteoblasts and osteoclasts. Bone is also a highly vascularised tissue which allows a ready supply of nutrients and proteins that stimulate bone repair. Furthermore, there is a large source of stem cells in the bone marrow and periosteum which can differentiate into osteoblasts. This allows bone to heal defects up to a certain critical size after which vascularisation becomes an issue. A thorough understanding of the composition and structure of the tissue will enable superior tissue engineering approaches to be explored to solve the clinical challenges of osteochondral defects.

Current clinical approaches, typically palliative, are ineffective at the early stages of tissue degradation and the tissue either continues to degrade, resulting in total replacement with an implant, or leads to the formation of fibrocartilage. Regenerative medicine and tissue engineering approaches have been widely explored to develop new approaches to repair and regenerate osteochondral tissue [7, 9-13]. These approaches often involve a combination of biomaterials, cells, scaffolds (temporary structures that allow cell attachment and tissue growth), and/or biomolecules (e.g. growth factors, cytokines, hormones, and nucleic acids) to develop a range of strategies for the repair, replacement, and regeneration of damaged tissues and organs. These strategies typically aim to mimic the biochemical and biophysical environment of the extracellular matrix (ECM) of the target tissue to promote a desirable cell response. Thus, the design and engineering of functional biomaterials and incorporation of bioactive molecules plays a major role in the development of clinically effective tissue engineering strategies. A key contributing factor to the success of these strategies rely on the fabrication technique utilised to generate the scaffolds which can be produced through conventional (e.g. electrospinning, solvent casting, particulate-leaching, gas foaming, and freeze drying) and additive manufacturing techniques (e.g. material extrusion, stereolithography, inkjet, and powder-bed fusion) [14, 15]. While conventional techniques and 3D printing technologies enable the fabrication of 3D scaffolds amenable to cell seeding, 3D bioprinting technologies afford the fabrication of 3D constructs through the simultaneous positioning of biomaterials and living cells in a prescribed layer-by-layer organisation The scaffold morphological parameters such as porosity, interconnectivity, 
and fibre diameter have a critical role in regulating cellular growth and behaviour, hence, the use of additive manufacturing technologies enables precise fabrication of complex structures that are not possible through conventional methods. A decisive development within tissue engineering is the advancement of three-dimensional (3D) bioprinting which offers a paradigm shift in the fabrication of complex multimaterial structures containing biomaterials, cells, and biomolecules $[14,16,17]$.

However, to date existing tissue engineering strategies have been unsuccessful in producing functional and mature articular cartilage. The fundamental tissue engineering approaches may need to be revaluated to understand why these approaches consistently fail in producing a relatively simple and thin tissue, although exhibiting a highly complex hierarchical organisation [18]. Adult articular cartilage takes over 20 years to mature and once formed the tissue does not turnover or regenerate unlike other tissues in the body. The tissue produced during childhood is the same throughout a person's lifetime. Malda et al. [18] suggest that new approaches must appreciate this fundamental aspect of cartilage tissue physiology which may potentially require the incorporation of constructs with precisely controllable degradation rates to match the exceptionally low remodelling of native cartilage ECM. These authors argue that biomechanical cues in addition to restoring the biochemical and biophysical microenvironment at the early stages of development (fetal and childhood) is essential to support the recapitulation of developmental processes underlying the restoration and formation of articular cartilage tissue. Furthermore, elucidating the underlying processes of cartilage development will provide a mechanistic understanding that will inform the rational design of tissue engineering approaches for cartilage regeneration.

This paper provides an overview of the structure, composition, and biomechanics of osteochondral tissue, along with currently available clinical treatments. We will then discuss the requirements and challenges in tissue engineering regarding suitable materials, biological factors, cellular and acellular scaffolds, the utilisation of 3D bioprinting technologies, and in vitro maturation techniques to provide a starting point for new researchers in the field. Finally, we highlight clinical developments and regulatory hurdles that should be considered during the research stage as well as the challenges still to overcome within the field.

\section{Osteochondral tissue}

There are three forms of cartilage in the human body including fibrocartilage [19], elastic cartilage, and hyaline cartilage each with their own specific biological, mechanical, and structural properties [20]. Hyaline cartilage is a thin tissue present at synovial joints such as the knee, elbow, shoulder, and hip where it covers the bearing surface of the underlying bone and is termed articular cartilage [21]. Articular cartilage is anchored to the subchondral bone and forms the osteochondral unit. Hyaline cartilage provides an efficient load bearing surface that has a low friction coefficient thus lubricating the movement of joints and can support load transfer of up to six times the human body weight in the knees [6]. The complex, nonlinear, viscoelastic, anisotropic, and heterogeneous structure and composition of cartilage enable these vital properties [22, 23].

\section{Composition of articular cartilage}

Adult articular cartilage consists of predominately ECM, approximately $95-99 \%$ of the total volume, which itself consists of $80 \%$ water and $20 \%$ solid contents [24]. The solid content is mostly comprised of collagens $(50-75 \%)$, proteoglycans (15-30\%), and a small amount of non-collagen proteins [21,25]. Cells account for a small percentage of the total volume (1-5\%) and consist of only a single cell type, chondrocytes [26]. The composition of articular cartilage changes as the tissue matures from initial formation during embryogenesis to final maturation (18-21 years old) [27].

The mature tissue has a low density of chondrocytes in a low proliferative and metabolic state, which are isolated from each other within the pericellular matrix and, therefore, lack cell-cell interactions [8]. This is partly responsible for the low healing capacity of mature articular cartilage. However, mature chondrocytes have an important role in the tissue homeostasis by coordinating and producing the ECM components. The morphology, orientation, and phenotypic expression of chondrocytes are depth and biomechanically dependent as the cells are influenced through mechanotransduction $[28,29]$. This results in the wide range of morphologies observed, which range from rounded, elongated, flattened, and hypertrophic, all within the same tissue [30].

The collagen network in articular cartilage is highly organised and primarily composed of collagen type II ( $\sim 50 \%$ dry weight of articular cartilage) [22]. It is assembled through procollagen polypeptides binding together to form collagen that assembles into micro-fibrils and then fibrils which can be cross-linked together by collagen type IX [31-33]. These collagen fibrils exhibit a characteristic banding pattern of $\sim 67 \mathrm{~nm}$ due to the staggered packing arrangement of collagen (Fig. 2a). The organisation is depth dependent in the tissue and is partly responsible for the biomechanics, especially the tensile and compressive properties [23]. The fibre diameter increases from the articular surface through the depth of the tissue (superficial zone $\sim 55 \mathrm{~nm}$, middle zone $\sim 87 \mathrm{~nm}$, and deep zone $\sim 108 \mathrm{~nm}$ ) [34]. Although collagen type II is the main collagen (95\% of total collagen), there are other collagens 


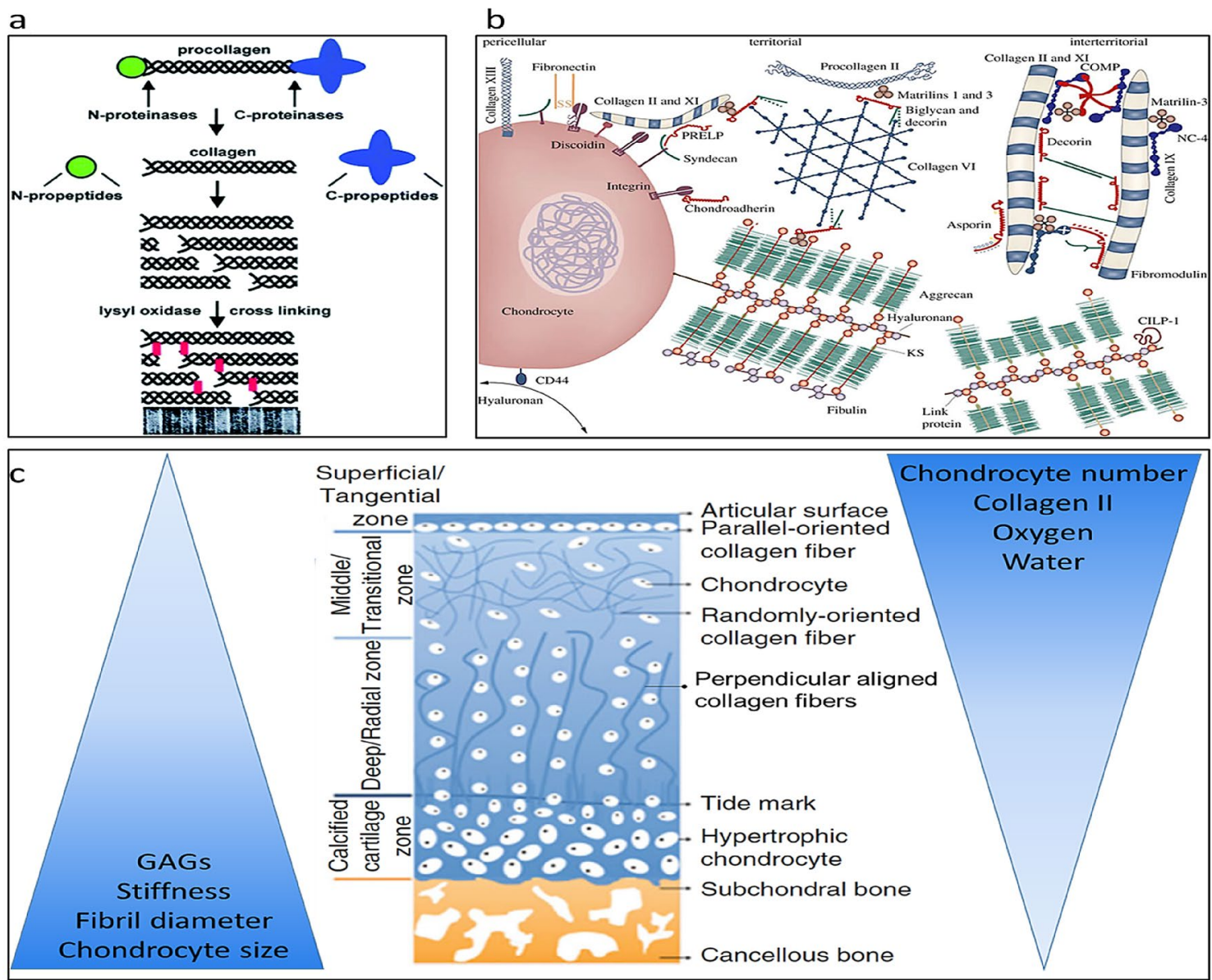

Fig. 2 Hierarchical and graded composition, structure, and properties of osteochondral tissue. a Collagen fibril assembly. Image from reference [33]. b Molecular composition and arrangement of the chondron depicting the pericellular, territorial, and interterritorial matrix

present such as type I, II, VI, IX, X, and XI. Collagen type $\mathrm{I}$ is present in small amounts only in the superficial zone, but can be found abundantly in fibrocartilage so can be used as a useful indicator of fibrocartilage formation [33, $35,36]$. Subsequently, the ratio between collagen I and collagen II can be used as a marker to assess the status of the cartilage tissue as chondrocytes cultured in vitro monolayer express higher levels of collagen type I indicating that the chondrocytes have undergone dedifferentiation [29]. Collagen IX and XI are found throughout the tissue in small amounts and are involved in crosslinking between fibrils, regulation of fibril size, and interactions with other biomolecules [22]. Collagen $\mathrm{X}$ is found in the deep and calcified zones and is believed to have a role in the mineralisation between the cartilage and the subchondral bone [37, 38]. A major non-collagenous component of the ECM are proteoglycans and glycosaminoglycan's (GAGs) [6]. Proteoglycans consist of a core protein that is heavily bound with covalently attached polysaccharide chains, with increasing distance from the chondrocyte. Image from reference [36]. c Zonal structure and properties of osteochondral tissue. Image adapted from [50]

GAGs. Aggrecan is a main proteoglycan within articular cartilage and is covalently attached to negatively charged GAGs, keratan sulphate and chondroitin sulphate. This is able to bind multiple times to a hyaluronic acid backbone to form aggrecan-hyaluronan aggregates which are highly negatively charged $[39,40]$. The negative charge on this proteoglycan aggregate, and other proteoglycans, causes an osmotic pressure to be generated as water is taken in and entrapped which causes swelling [37]. This turgidity produced by the network of proteoglycans combined with the structural confinement caused by the organisation of collagen results in a high compressive modulus $[3,29]$. Subsequently, as the concentration of proteoglycans increases with depth in articular cartilage towards the subchondral bone region, the water content and swelling pressure rises, thus the compressive modulus of the tissue increases [12, 41-43]. This enables articular cartilage to have a high mechanical load bearing capability which can transfer and distribute loads effectively [43]. 


\section{Structure of osteochondral tissue}

Articular cartilage has a hierarchical organisation from the nanoscale to the macroscale with a distinct zonal structure. Each zone has its own specific ECM composition, biomolecule orientation, chondrocyte shape and organisation [44], imparting specific biomechanical characteristics (Fig. 2c). These zones are termed, descending from the articulating surface, the superficial or tangential zone, the middle or transitional zone, the deep or radial zone, and the calcified zone, before the articular cartilage gives way to the subchondral bone region. Furthermore, there is a microscale radial organisation surrounding the chondrocyte termed the chondron which has a unique composition depending on the distance from the chondrocyte (Fig. 2b).

On the articular surface and above the superficial zone is a thin layer, ranging from a few hundred nanometres to a micrometre, termed the lamina splendens which is acellular and composed of proteins [45]. Although the lamina splendens role is unclear it is thought that the gradual build-up of proteins from the synovial fluid acts as a protective and low friction interface for the articular cartilage surface [35].

Immediately below the lamina splendens is the superficial zone (10-20\% of cartilage thickness), which comprises small diameter collagen fibres (predominately type II and IX) that are organised parallel to the articular surface and densely packed. This allows a low coefficient of friction, which enables smooth movement of the joint and imparts the ability to withstand both the high tensile and shear stresses that the articular cartilage encounters under loading. The chondrocytes are densely packed and arrange themselves along the collagen fibres parallel to the surface, displaying a flattened morphology. Chondrocytes also secrete proteins such as superficial zone protein (SPZ, also known as lubricin or PGR 4) and collagen I which act as lubricants [22, 46-48]. SPZ is a potential marker to identify this zone. The amount of proteoglycans is low compared to the other zones which increases the permeability, thus resulting in compressive strains of up to $50 \%$ and high fluid flow which influences the compressive properties of the entire cartilage tissue $[22,23,39,49]$.

Below the superficial zone is the middle zone (40-60\% of cartilage thickness), which is predominately composed of collagen II fibres randomly arranged and displaying a larger diameter than the superficial zone. Chondrocytes are present at a lower density, display a rounded morphology, and express large quantities of collagen II and aggrecan. A marker for this zone is the cartilage intermediate layer protein which is expressed throughout this zone [38]. This zone also has the highest concentration of proteoglycans especially aggrecan $[49,51]$.

The deep zone (20-50\% of cartilage thickness) is comprised of the largest diameter collagen fibres that are oriented perpendicular to the subchondral bone region with the chondrocytes organised along the collagen fibres in columns with an elongated morphology. The cells themselves are present in lower density compared to the other zones and express lower levels of collagen II [51, 52].

The final zone before the subchondral bone region is the calcified zone which is distinguished from the deep zone by the presence of a tidemark which demarks the boundary between calcified and non-calcified regions [53, 54]. The zone anchors the collagen fibres of the deep zone to the subchondral bone thus integrating the cartilage to the underlying bone. This also provides an interface between the hard phase of bone and the soft phase of cartilage since the presence of hydroxyapatite reduces the mechanical gradient between the phases [22, 40,55]. The calcified zone also has the highest number of chondrocytes which are in a hypertrophic state.

The final zone of the osteochondral tissue is the subchondral bone which lies directly below the calcified zone and separates the articular cartilage from the bone marrow. This zone consists of the bony lamella (cortical endplate) and the subarticular spongiosa (supporting trabeculae and bone components), which is separated from the calcified zone of articular cartilage by a cement line $[1,56,57]$. The subchondral bone differs markedly in composition and structure to the articular cartilage. The subchondral trabeculae are highly vascularised which acts as a nutrient source for articular cartilage enabling transportation of nutrients, gases, and waste through channels that cross the subchondral bone plate and enter the calcified zone, apart from these channels the tissue is entirely reliant on the surrounding synovial fluid as a source of nutrients [42, 56, 57]. The main collagen is type I due to the tissue being mineralised bone. These collagen fibres do not cross between the calcified cartilage and subchondral bone region, so it does not act as an anchor as occurs with collagen fibres that cross the tidemark and connect the non-calcified and calcified cartilage. Furthermore, the subchondral trabecular structure and mechanical properties are anisotropic and the subchondral bone can dynamically remodel itself to respond to applied forces [58-60]. The main function of the subchondral bone is to maintain joint shape and provide mechanical support since it has a high compressive modulus and is impermeable, so is able to stabilise the tissue and distribute the applied mechanical forces [22, 39, 56, 61, 62].

\section{Current osteochondral treatments}

The zonal structure of osteochondral tissue and the innate inability of articular cartilage for self-regeneration poses a problem for clinical interventions. Hence, there are a variety of clinical treatments available which bring with them different degrees of success as well as tissue engineering 
approaches which are predominantly in clinical trial phases rather than in mainstream use in clinical practice [10, 63-66].

The main treatment strategies currently used worldwide are classified into (1) microfracture, (2) autologous chondrocyte implantation, (3) matrix-induced autologous chondrocyte implantation, (4) osteochondral auto- and allo-grafts, (5) autologous matrix-induced chondrogenesis, and (6) bone marrow aspirate concentrate (Fig. 3) [7, 12, 13].

The type of treatment used will depend on the defect category, stage, size, and location. Osteochondral defects are commonly classified by the Outerbridge classification system which indicates the severity of a lesion. This system classifies defects from grade $\mathrm{I}-\mathrm{IV}$, where a grade $\mathrm{O}$ defect is normal healthy articular cartilage (Fig. 4a); grade I indicates swelling and softening of the tissue; grade II indicates a partial thickness defect with a diameter less than $1.5 \mathrm{~cm}$; grade III defect has a diameter greater than $1.5 \mathrm{~cm}$ and presents as a full thickness lesion up to the subchondral bone; and grade IV is a full thickness defect that exposes the subchondral bone.

Patients with clinical conditions causing cartilage loss present either discrete cartilage loss in a joint surface or full thickness cartilage degeneration (Fig. 4b, c) [67]. Discrete areas of cartilage loss, e.g. osteochondritis dissecans, often caused by trauma, affects the younger population, whereas full thickness cartilage loss in the whole joint affects more elderly patients and is as a result of a systemic disease such as rheumatoid arthritis or osteoarthritis [66, 68, 69].

When considering discrete small areas of cartilage loss, patients present with pain due to exposed bone and

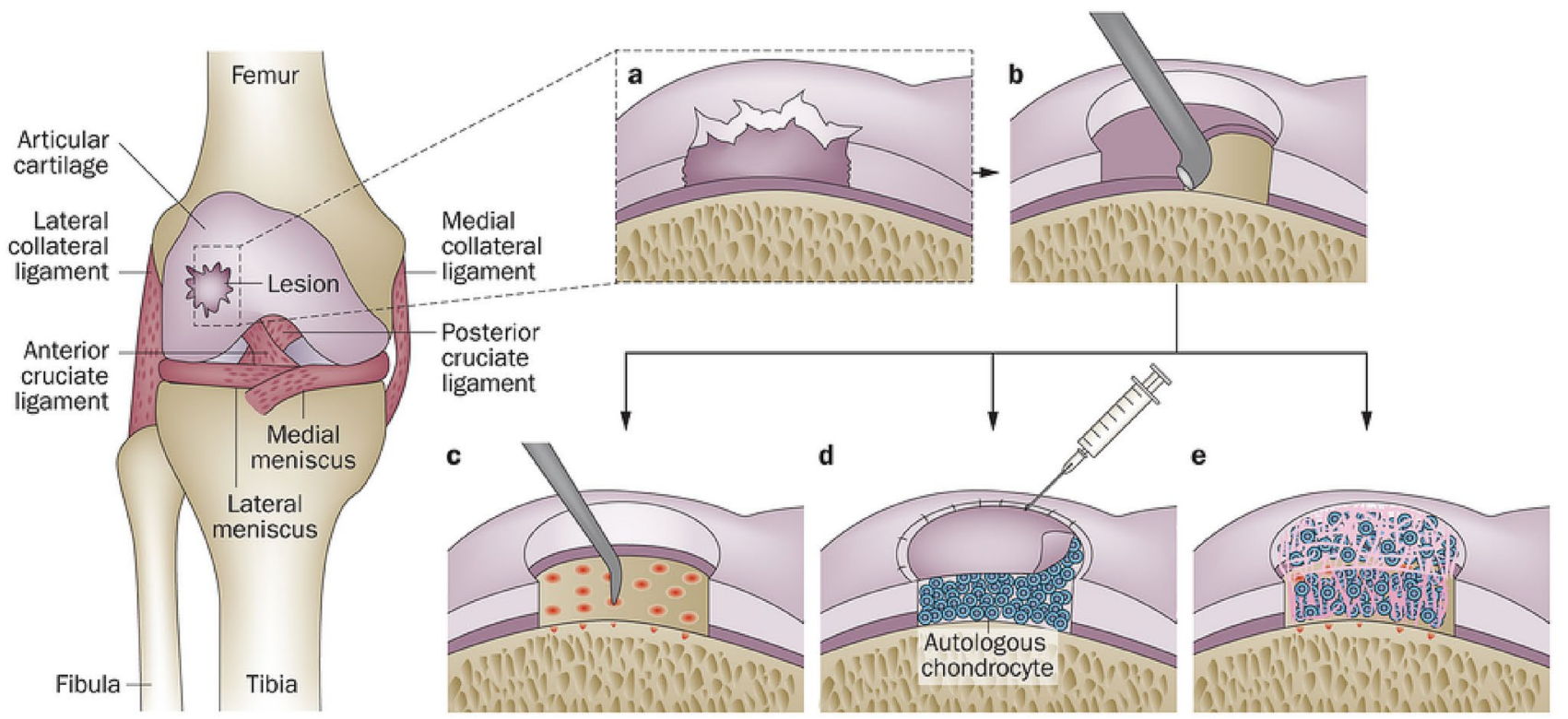

Fig. 3 Current treatment options for cartilage regeneration. a A fullthickness chondral lesion (Grade III). b The defect is debrided to remove damaged cartilage and bone to create a healthy border which enables improved tissue integration. c Microfracture drills into the subchondral bone to create channels that allow a blood clot to form in the defect. d Autologous chondrocyte implantation uses chondrocytes which are inserted into the defect and covered with a periosteal patch or a collagen membrane. e Matrix-induced autologous chondrocyte implantation, chondrocytes are cultured in vitro and seeded onto an absorbable 3D scaffold, then implanted into the defect, and fixed to the defect with fibrin glue. Image from [12]

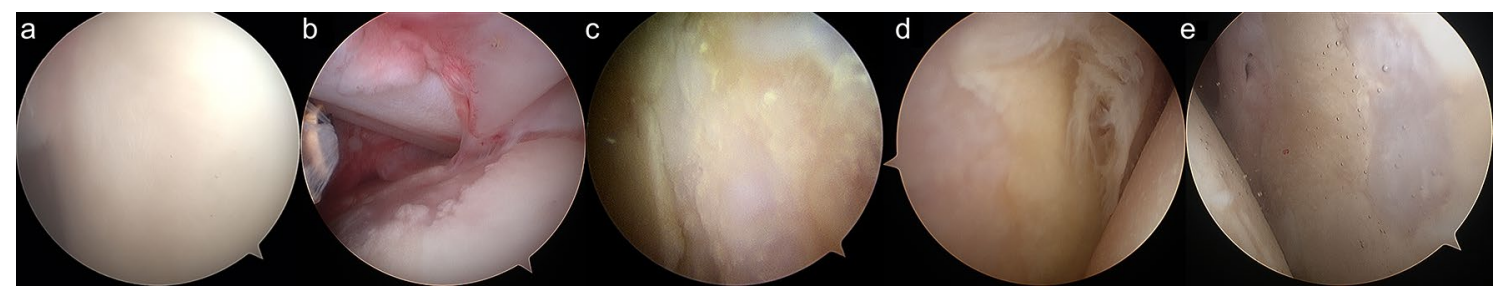

Fig. 4 a Normal healthy cartilage, $\mathbf{b}$ discrete cartilage defect, $\mathbf{c}$ full thickness area of cartilage loss, $\mathbf{d}$ end stage arthritis, and $\mathbf{e}$ fibrocartilage formed next to hyaline cartilage after microfracture surgery 
mechanical symptoms (e.g. joint locking), due to the disruption in the smooth low friction joint surface.

Current solutions have failed in restoring hyaline cartilage surfaces of the joint [70]. The most common surgical procedure to address small areas of cartilage loss is arthroscopic (keyhole) surgery, called debridement, which uses mechanical shavers to remove debris from the joint and loose cartilage material, solving some of the mechanical symptoms [71]. The aim of the surgery is to remove all loose material and roughen the surface of the exposed bone enough to allow new tissue to adhere and form in the base.

Due to the unpredictable results from debridement, alternative techniques have been developed to enhance biological healing in the cartilage defect with a variety used worldwide. The microfracture technique, popularised by Steadman since the 1980s [72, 73], involves the defect area being debrided to ensure a clean and stable margin before making $3 \mathrm{~mm}$ perforations in the subchondral bone, ensuring that the structural integrity of that bone is not compromised. This induces bleeding and allows a blood and bone marrow super clot to form in the above space creating an environment for multipotent marrow cells such as mesenchymal stem cells (MSCs) to differentiate and form a stable tissue. This super clot subsequently remodels into fibrocartilaginous tissue over a period of 12-16 months and requires a lengthy postoperative rehabilitation period with limited mechanical loading $[48,74]$. In one study, biopsies after microfracture treatment noted that $11 \%$ had formed predominantly hyaline cartilage and $17 \%$ a mixture of fibrocartilage and hyaline cartilage within them. The remaining patients formed either predominantly fibrocartilage or no tissue at all (Fig. 4e) [75, 76].

Although considered the gold standard by the FDA and some clinicians, the long-term outcomes for joint functionality using microfracture technique has shown limited improvement $[46,47]$. This is due to the inferior biomechanical and biochemical properties of fibrocartilage compared to hyaline cartilage, which creates a mismatch between the native tissue and the neotissue $[49,77]$. The treatment provides a short-term benefit to the patient but only postpones cartilage degeneration as the repair tissue typically deteriorates approximately 18-24 months after surgery [49]. Subsequently, five years after surgery the likelihood of treatment failure is high irrespective of the cartilage defect [46, 47]. This technique can also be combined with other treatment methods and an advancement on the technique utilises a collagen matrix that is inserted into the defect to promote MSC differentiation into chondrocytes [51].

With continued poor results from microfracture due to a lack of differentiation of new tissue, further treatment options have been developed, such as the use of bulk osteochondral auto- and allografts, or a procedure termed mosaicplasty, which involves the transplantation of osteochondral tissue from either the patient (autograft) or a tissue donor (allograft) [59]. Mosaicplasty involves taking a small osteochondral plug/biopsy from the periphery of weight bearing joints, for example, the margins of the femoral condyles in the knee (non-loading or minimal loading region). This is then transplanted into the defect, which has been prepared with only healthy tissue remaining, and the graft is subsequently aligned with the native tissue. Mosaicplasty has been shown to have better results than microfracture, though there are a number of limitations to the technique $[46,60,61]$. The use of autografts is limited due to the need to restrict donor site morbidity which results in only small defect sizes $(<4$ $\mathrm{cm}^{2}$ ) being treated and the lack of integration of the periphery of the plugs with each other or the native hyaline cartilage [78]. Furthermore, the use of allografts (osteochondral material from a deceased donor) raises the potential issue of disease transmission and immunogenicity, however, the size of defect treated can be larger as the tissue is derived from cadavers. Finally, and most importantly when comparing this against other treatment modalities, graft failure has been observed in up to $55 \%$ of patients after 10 years due to poor integration with the host tissue, often a major limitation with other techniques as well, and degradation of the allograft [62].

Autologous chondrocyte implantation (ACI) techniques have been in use since the first reported series in 1987, which was developed as an improvement on the microfracture technique $[7,12,52,53,79]$. The technique is a two-stage surgical procedure that first involves harvesting autologous chondrocytes using an arthroscopic (keyhole) technique from a minimal load bearing region through a biopsy punch and expanding these cells in vitro to obtain a population of approximately $12-48$ million cells. In the second surgery, performed using an open approach rather than arthroscopic, the defect area is debrided, and the cell suspension is seeded into the defect area and confined to the defect by membrane coverage. The membrane used is typically a periosteal patch, however a major cause of treatment failure is hypertrophy of the patch which can give rise to mechanical symptoms and aching similar to the original problem [54]. Subsequently, synthetic collagen or hyaluronic acid patches have been utilised, showing reduced failure rates (5-26\%) due to patch hypertrophy [55]. However, these synthetic patches are considered as off-label in the USA due to the sourcing of the material from allogenic sources which may increase the chance of a negative immune response and rejection [12]. ACI has been shown to be effective through clinical trials which demonstrated positive functional and clinical outcomes in the early years following treatment and formation of hyaline-like tissue. This is potentially due to the use of autologous chondrocytes which have a greater inherent ability to form hyaline cartilage than MSCs. However, new tissue that is not morphologically or histochemical identical to normal hyaline cartilage and fibrocartilaginous 
tissue was shown to develop in the majority of patients. This may be a result of the in vitro culturing stage as studies have demonstrated that chondrocytes dedifferentiate into fibro-chondrocytes in 2D culture, however, other studies have shown that by culturing the cells in a 3D and hypoxic environment this can be reversed [56, 57]. There are further limitations to ACI which include the need for two invasive surgical procedures combined with in vitro culturing and the subsequent long recovery period (6-12 months) needed to ensure successful neotissue formation.

A derivative of the ACI technique is matrix-induced autologous chondrocyte implantation (MACI), which can be considered as a tissue engineering approach as it utilises a scaffold to assist in cell attachment, distribution, and proliferation, guiding new matrix formation. MACI is similar to $\mathrm{ACI}$ in that it requires the initial isolation of autologous chondrocytes from the patient and in vitro cell expansion, however, seeding is then carried out onto the scaffold, which can be made of collagen or hyaluronic acid. The cell-seeded scaffold is then cultured in vitro before implantation into the debrided defect and fixation with fibrin glue. The clinical advantage of MACI over other techniques remains to be confirmed as current clinical trial data has shown that MACI either has similar or better functional results, thus is not widely utilised yet clinically. However, MACI has the same limitation as ACI due to the requirement of two surgical procedures. Furthermore, the tissue matures slowly and long recovery periods are required. However, the long recovery periods may happen with any treatment due to the nature of the limited regenerative capacity of articular cartilage. There are a number of benefits to using a scaffold based treatment such as easier fitting of the graft into the defect, improved graft stability, and better control in preventing dedifferentiation of the chondrocytes due to fact that cells are cultured in a 3D matrix which reduces the formation of fibrocartilaginous tissue $[12,58]$.

Alternatively, autologous matrix-induced chondrogenesis (AMIC) has been used to repair chondral and subchondral defects. This procedure is a single-step surgery that can be performed both arthroscopically or openly and consists of initial debridement of the defect, microfracture of the underlying bone to form a super clot, and the placement of a resorbable membrane to form a protected clot. The membrane is sealed in place either with a fibrin glue or suturing. This protected blood clot provides a conducive environment for cartilage regeneration and the formation of hyaline-like cartilage. The membrane allows the entrapment of the blood clot, MSCs, and growth factors and is typically made from porcine-derived collagen I/III, however, hyaluronic acid and polyglycolic acid have also been utilised [80]. AMIC is advantageous compared to ACI and MACI as no in vitro cell expansion steps are required, no second surgical procedures is necessary, and there is no donor site morbidity.
Randomised control trials show that AMIC using a collagen membrane had significant improvement and stability in clinical results after five years compared to microfracture alone [81]. However, fibrocartilage formation was observed in histological evaluation of two patient biopsies, indicating that chondrogenesis into a hyaline phenotype is restricted. Furthermore, there is limited high-quality randomised control studies to provide evidence of the superiority of AMIC over typically used procedures such as microfracture and ACI thus further studies are required to assess its efficacy and clinical relevance in a range of joint defect conditions [82].

Finally, when considering the treatment of discrete cartilage defects, bone marrow aspirate concentrate (BMAC) has been recently explored to augment existing osteochondral repair techniques and can be used as a primary treatment option [83-86]. The bone marrow aspirate, typically derived from the iliac crest, contains a range of cellular components which are further isolated and concentrated, through density gradient centrifugation, to produce a BMAC which is rich in bone marrow derived MSCs, platelets, haematopoietic stem cells, and growth factors. This concentrated source of stem cells and growth factors can promote chondrogenic and osteogenic responses, migration and recruitment of cells, and vascularisation. Animal and human clinical trials have shown that the procedure is safe and has promising positive outcomes with improved cartilage repair. Although still inferior to hyaline cartilage tissue, BMAC enhances repair when used in conjunction with microfracture and matrixassisted procedures [83-85, 87-89]. What makes this technique agreeable to both surgeons and patients alike, is that it is simple and technically easy to perform as well as having minimal donor site morbidity compared with other techniques. However, currently no standard procedure for BMAC is available, thus, aspects of the concentrate such as cell and growth factor type and concentration will vary between individuals which will influence the quality of tissue repair and clinical outcome.

Whole joint osteoarthritis represents a different clinical challenge. Not only is the articular cartilage damaged, but the subchondral bone becomes deformed and the periarticular capsule, muscles and tendons become affected. Current treatment strategies are dominated by joint replacement surgery [90]. Since the development of the successful low friction arthroplasty by the late Sir John Charnley, the metal on high molecular weight polyethylene bearing surfaces have been widely used in total joint prostheses. In the UK over 160,000 hip and knee replacements are carried out each year [91]. However, the challenge continues to overcome the mechanical loosening of these prostheses over time. In additional cellular regeneration strategies are unlikely to overcome the structural changes in all of the tissues types that are involved [92]. Revision surgery to replace failed prostheses causes not only significant morbidity to the 
patient but also the results of the second or subsequent joint replacement being significantly inferior to primary procedures. There is an associated substantial financial burden to the healthcare system due to increased cost of peri-operative investigations, blood transfusions, surgical instrumentation, implants and operating time, as well as an increased length of stay in hospital which accounts for most of the actual costs associated with surgery. Prosthetic innovation has been able to reduce the incidence of implant failure by improving the techniques employed to ensure good integration with the host bone, e.g. coating implants with hydroxyapatite and using uncemented implants.

As previously described, current clinical techniques for cartilage repair are promising, however, positive clinical outcomes rarely last more than 5 years and often gradually deteriorate over this period. None as of yet have fully repaired either an articular cartilage defect or a full osteochondral defect over the long-term. Furthermore, techniques such as ACI, MACI, and BMAC are limited to chondral defects only and are not suitable for osteochondral defects. However, as no other superior alternatives are available, these procedures continue to represent the mainstay of clinical management despite their failure to recreate hyaline cartilage. All the approaches described have significant limitations which not only fail to recapitulate the native structure and result in mechanical mismatch with failure over the long-term. Additionally, these techniques are associated with multiple procedures, donor site morbidity, and long rehabilitation periods following treatment. Subsequently, long-term failure in these procedures can result in significant tissue degradation causing pain and limited mobility, thus potentially requiring a total joint replacement. New tissue engineering strategies are appealing as they might enable rapid weight bearing and fully integrated neotissue that subsequently develops into phenotypic and functional hyaline cartilage. These new clinical therapies are required to enhance the quality of life of patients and reduce the economic burden to healthcare systems.

\section{Tissue engineering: requirements and strategies}

Tissue engineering is a multidisciplinary field of research conducted to meet clear clinical requirements of therapies to promote the regeneration and repair of diseased and damaged tissues. Tissue engineering approaches in cartilage regeneration and repair have great potential and provide an alternative to current available therapies which are inadequate, however, challenges remain [7, 9-12]. Engineered cartilage constructs are comprised of biomaterials, cells, and/or stimulatory factors (e.g. growth factors and biomechanical stimulation), which are considered key to the design of functional cartilage tissue (Fig. 5) [93, 94]. Key cell sources explored for seeding of scaffolds or encapsulation include chondrocytes [95], mesenchymal derived stem cells (e.g. bone, adipose, synovium) [7, 10, 96-98], induced pluripotent stem cells [99, 100], embryonic stem cells [101], and pericytes [102].

However, the current paradigm still lacks in the development of long-term phenotypically stable articular cartilage tissue which exhibits integration with the surrounding tissue, mechanical stability, and withstands inflammatory factors, especially in a diseased environment such as osteoarthritis.

\section{Biomaterials design and selection}

Biomaterials are the backbone of 3D engineered constructs and support tissue growth and formation by providing a biomimetic environment to the native tissue and structural integrity during maturation to allow cell proliferation, cell to cell communication, and ECM formation. The ideal design specifications of 3D tissue engineered scaffolds from the biomaterials perspective include: (1) biocompatibility, cell viability with a desired cellular behaviour; (2) biodegradability, the scaffold degrades at a controlled rate which matches tissue formation; (3) provides mechanical and biochemical cues to promote a desired cellular response. An alternative strategy to the use of biomaterials is cell selfassembly approaches such as spheroid formation which does not require supporting materials [103, 104].

Biomaterial scaffolds can be produced from different sources such as naturally derived polymers, synthetic polymers, and ECM derived materials.

Naturally derived biopolymers have been explored extensively for cartilage tissue engineering applications $[11,105$, 106]. The most associated advantages with naturally derived polymer is their capacity of supporting cell attachment, viability, proliferation, attachment, and differentiation, and, in some cases, maintenance of cell phenotype [107]. This is mediated in protein derived biopolymers through binding motifs present in the polymer. Despite these key advantages, naturally derived polymeric materials present some drawbacks such as poor degradation kinetics, limited processability, and mechanical properties. However, these limitations may be improved through the modification of the polymer backbone or via crosslinking mechanisms [107]. For example, gelatin is commonly modified by reaction with methacrylic anhydride to form gelatin methacryloyl (GelMA) which contains both methacrylamide and methacrylate side groups [108-110]. This enables the formation of hydrogels via photo-mediated crosslinking in the presence of a photoinitiator and the use of a suitable wavelength of light. This aids in biofabrication processes, especially in 3D bioprinting, as the gel can be rapidly crosslinked after material deposition or cell encapsulation. Furthermore, the mechanical 


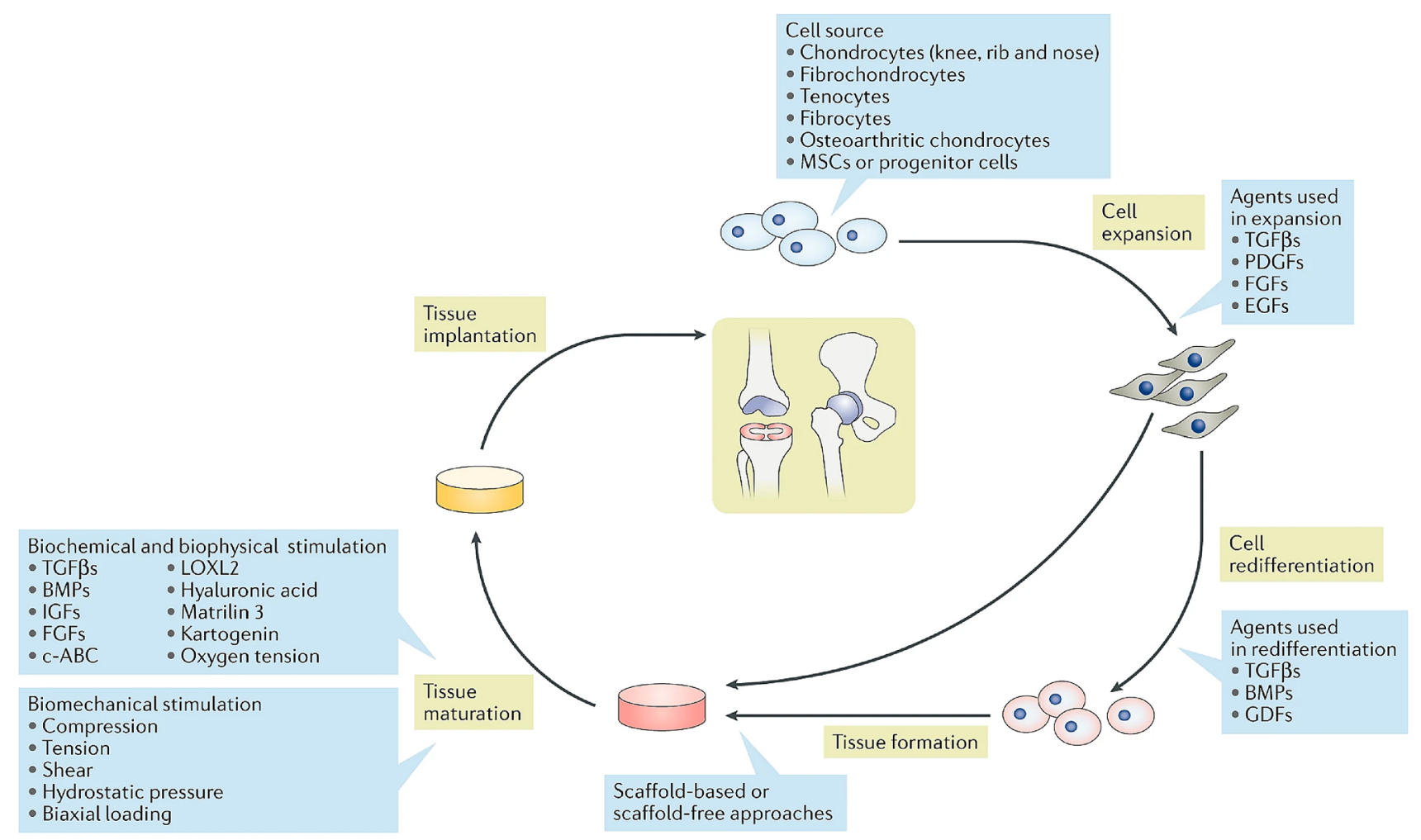

Fig. 5 Tissue engineering strategies for articular cartilage regeneration. Image from [10]

and morphological (e.g. porosity and pore size) properties of tissue constructs can be tuned by selecting the appropriate reaction and crosslinking conditions. Additionally, the cell binding arginine-glycine-aspartic acid (RGD) motifs and matrix metalloproteinase (MMP) degradable sequences are retained within the modified gelatin, thus maintaining biocompatibility, and bioactivity, while allowing cell-material interaction and cell-mediated hydrogel degradation.

Naturally derived polymeric materials can be classified into two main categories:

1. Polysaccharides: gel forming polysaccharides such as alginic acid and mucopolysaccharides (glycosaminoglycans), storage polysaccharides which include starch and glycogen, and structural polysaccharides such as cellulose and chitin.

2. Protein based polymeric material composed of amino acid groups such as collagen, gelatin, and silk fibroin. Proteins can be classified by their shape, size, solubility, composition, and function.

Synthetic polymers have shown potential in tissue engineering due to their improved mechanical and degradation properties with the capacity to be more easily chemically modified or engineered to tune their properties [111-113]. The hydrolytic and enzymatic degradation of the polymer can be controlled through modification of the polymer [114]. However, due to lack of biologically functional domains, which can reduce the risk of immune response, synthetic polymers may not facilitate cell phenotype expression or cell attachment as occurs in naturally derived protein-based polymers. Several strategies have been pursued to tackle this limitation, including the blending with bioactive polymers and the functionalisation of polymer backbone with cell-adhesive cues $[115,116]$. Among synthetic polymers, PCL and poly(ethylene glycol) (PEG) have been the most extensively used to create mechanically robust 3D scaffolds with intricate geometries and 3D cell-laden hydrogels, respectively. PCL has been processed via melt extrusion and melt electrospinning to engineer acellular scaffolds which pores can be eventually filled with cell-laden hydrogels or cell spheroids towards creating biomimetic cartilage tissue constructs [117-119] In turn, PEG functionalised with a variety of reactive groups has been explored to produce cell-instructive hydrogels with tuneable properties through several crosslinking chemistries, sustaining cartilage formation [115]. Recent works have explored dynamic covalent chemistries to engineer covalent adaptable networks with controllable viscoelasticity and stress relaxation, recreating such features of the native cartilage. As an example, Richardson et al. [120] cultured porcine chondrocytes within stress relaxing hydrazone crosslinked PEG and observed an 
increased deposition of collagen (e.g., collagen type II) and sulfated glycosaminoglycans (e.g., aggrecan) in hydrogels exhibiting stress relaxation compared to predominantly elastic hydrogels with slow average relaxation times. Results suggest that a fine control over the hydrogel viscoelasticity is essential to preserve gel network integrity, while supporting the formation of high-quality neocartilaginous tissue.

Decellularised extracellular matrix ( $\mathrm{dECM}$ ) based biomaterials have also been explored to create $3 \mathrm{D}$ constructs. The native ECM is ideal for tissue engineering as it is identical to the desired matrix structure required and helps controls cell behaviour [121-126]. Thus the use of dECM is suitable as it is biodegradable, does not produce antagonistic immune responses, provides cues for cell differentiation, and presents bioactive molecules that determine tissue homeostasis and tissue regeneration $[121,127,128]$. The replication of the ECM microenvironment has provided inspiration to use the ECM from articular cartilage as matrix for tissue regeneration [127, 129]. Benders et al. demonstrated the fabrication of a decellularised cartilage tissue derived scaffold. This process comprises mechanical (grinding/milling of large tissue slices) and chemical (enzymatic and detergents) manipulation to remove the cellular components to allow formation into a scaffold structure which showed promising early-stage production of cartilage specific matrix [130, 131]. Furthermore, bioinks based on dECMs have been developed offering an additional route for their use in tissue engineering applications [132-134]. The source of dECM, either derived from cartilage tissue or cellular has potentially an impact on cell behaviour with tissue-derived matrices showing greater chondrogenic differentiation whilst cellular-derived matrices facilitated enhanced cell proliferation and chondrogenic potential, although further investigation is required to understand the discrepancies [121]. Decellularisation protocols from harvesting, decellularisation, and sterilisation to creating the dECM based scaffolds affects the hydration status and 3D configuration of the proteins and ECM, and hence strongly influences biomechanical and biological behaviour properties which may not be suitable anymore $[122,135]$. Furthermore, concerns remain about potential immunogenicity and poor biomechanical and biological performance.

The selection of suitable biomaterials, biofunctionalisation strategies and processing technologies are essential to engineer a cell- and tissue-specific environment that promotes desirable cell behaviour and functional tissue formation (Fig. 6). Each class of biomaterials has their own advantages and disadvantages, thus, there is difficulty in selecting only a specific class of biomaterial for use in osteochondral tissue engineering. Despite the limited long-term evidence of clinical outcomes currently, many ongoing trials and early-stage outcomes are positive and report encouraging results $[10,13]$. Subsequently, the development of advanced hydrogels which can combine the advantages of both synthetic and natural polymers, for example, in hybrid systems and synthetic self-assembling peptides are promising solutions [136, 137].

\section{Bioprinting cartilage tissue}

The advancement of 3D printing and 3D bioprinting in tissue engineering has allowed the fabrication of scaffolds and biological tissue models that more accurately reflect the complex organisational structure and material properties of tissues and organs $[14,139]$. 3D bioprinting uses biomaterials, cells (encapsulated or seeded), and biomolecules, typically referred to as a bioink, which are precisely deposited in a layer-by-layer process to build-up a 3D structure. The ability to print multiple cells and biocompatible materials with greater design freedom compared with conventional fabrication techniques has enabled the development of 3D structures that resemble the complex 3D biophysical and biochemical environment in tissues. The use of 3D bioprinting within cartilage tissue engineering is becoming widespread as an enabler technology to fabricate complex multimaterial structures that mimic, in some extent, the biological and mechanical properties of cartilage tissue $[15,140]$. Currently, 3D bioprinting predominately uses inkjet, extrusion, and laser-assisted systems to fabricate 3D structures (Fig. 7). However, stereolithography based systems are gaining attention due to the development of novel visible light photoinitiators with improved cytocompatibility and advancements in the technology which promises faster fabrication times and increased structure complexity [141-143].

The development of bioinks has become an essential factor for the success of 3D bioprinting, in particular, biomaterials with controllable mechanical, biological, and biophysical characteristics which can modulate cell behaviour combined with printability (Fig. 8) [17, 145, 146]. Printing resolution, structure fidelity, material viscoelasticity are crucial parameters in determining the printability of bioinks and its relationship to the final mechanical and biological properties of the structure. Developing advanced bioinks requires consideration of pre-functionalisation processes to incorporate biological functional groups and crosslinking moieties, the rheological behaviour of the bioink to ensure printability and fidelity, and the crosslinking method to ensure rapid gelation of the hydrogel [147-150]. More importantly, such requirements must also have in consideration that cell behaviour and functional properties of the new tissue depend not only on the bioprinting parameters (e.g., shear stress, crosslinking conditions), but also on the cell microenvironment provided by the engineered materials [151]. Depending on the biofabrication process and material properties, the bioink polymers will have various chemical and physical 


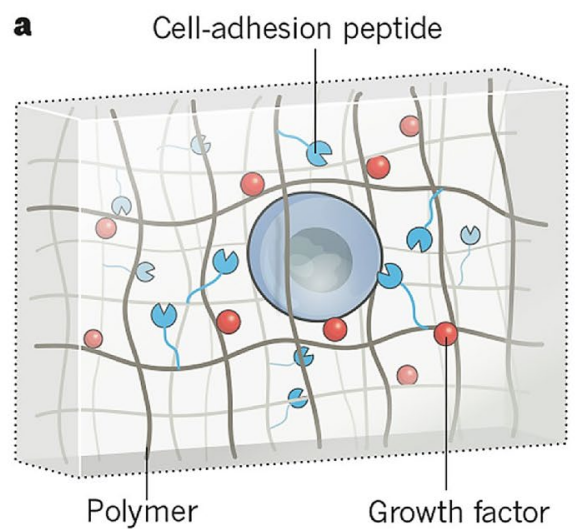

C

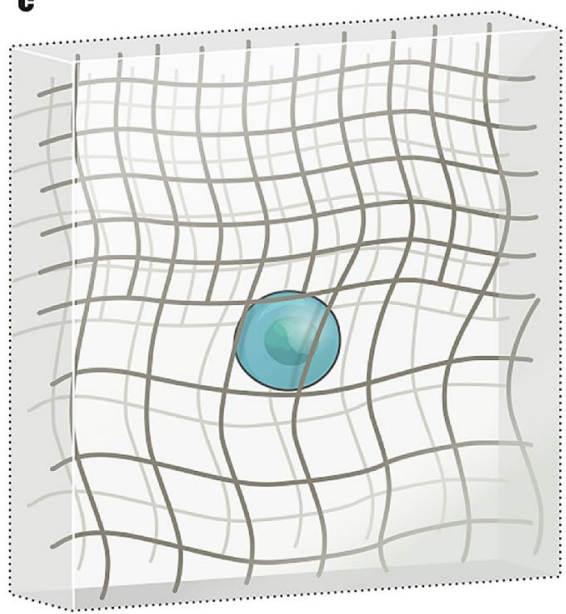

b

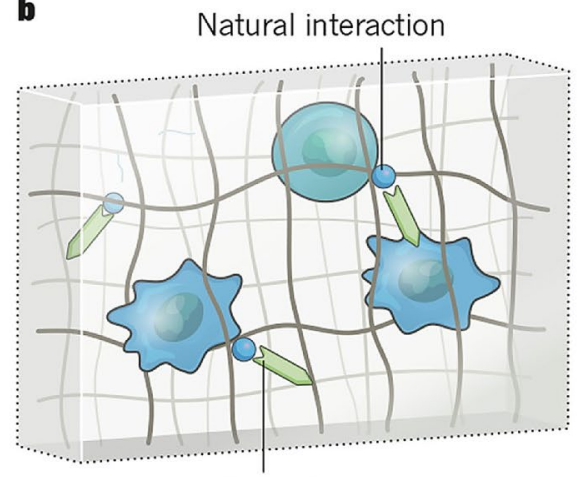

Cell mimic d

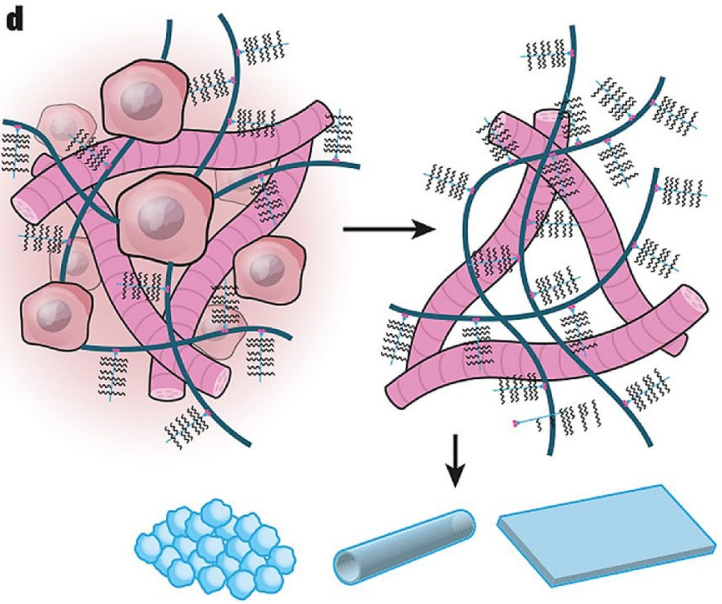

Particles, tubes, sheets e

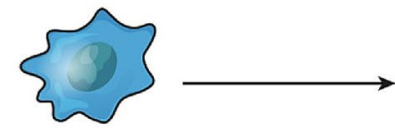

Cell migrates into scaffold

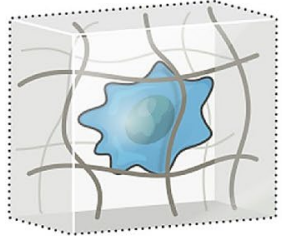

Scaffold instructs and educates cells

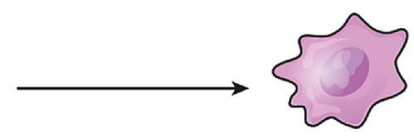

'Educated' cell migrates from scaffold
Fig. 6 Engineering biomimetic materials to generate tissue-specific microenvironments. a Natural and synthetic hydrogels can be engineered to contain peptides and proteins (e.g. cell binding sites and growth factors). b The hydrogels can mimic the native extracellular matrix through incorporation of cell-sensitive degradable crosslinks and proteins. $\mathbf{c}$ Biomechanical properties of the hydrogel can be regulated by exploring different chemistries allowing to independently

characteristics that will determine the corresponding application [152]. These properties can be determined by rheological characterisation, mechanical assessment and crosslinking properties of the hydrogel $[152,153]$. Shear-thinning behaviour, a decrease in the viscosity as a function of increasing shear rate, is crucial for bioprinting applications, since the material will flow with an applied tune the crosslinking density. d Native extracellular matrix in tissues and organs can have their cells removed through a decellularisation process to produce scaffolds with different forms such as particles, tubes, and sheets. e Cell migration and recruitment into functionalised biomaterials can be further explored to modulate their behaviour and enhance regenerative responses. Image from [138]

force during printing and the lower the applied force the higher the cell viability $[16,150,154]$. The viscoelastic behaviour characterised by the material response during printing needs to be optimised as low viscous materials will deform and collapse during printing, unless a rapid crosslinking process can be initiated. On the contrary high viscosity materials can be difficult to print as they can 
Fig. 7 3D bioprinting technologies commonly used in tissue engineering. Adapted from [144]

Vat polymerization

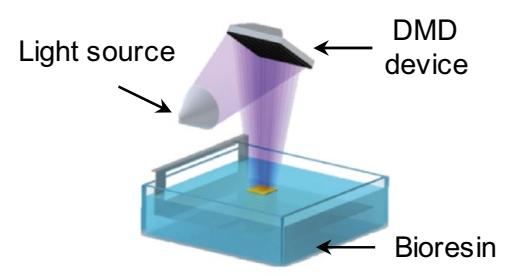

Laser-assisted bioprinting

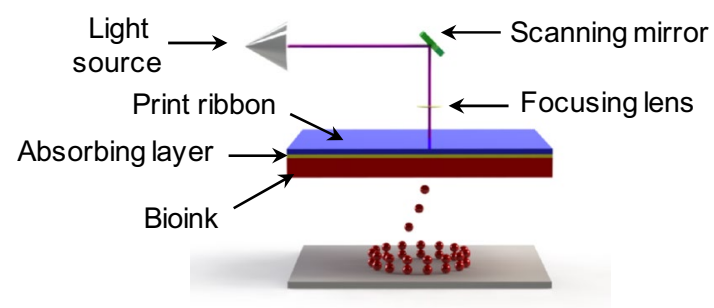

(a)

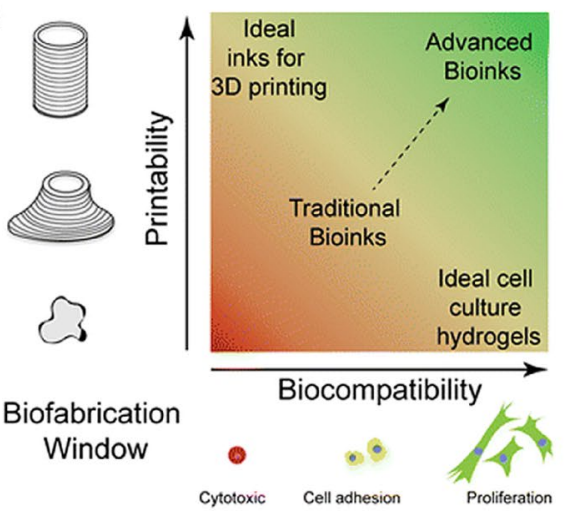

Inkjet bioprinting

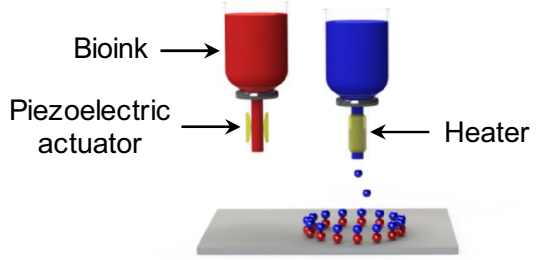

Extrusion-based bioprinting

Piston Pneumatic Screw

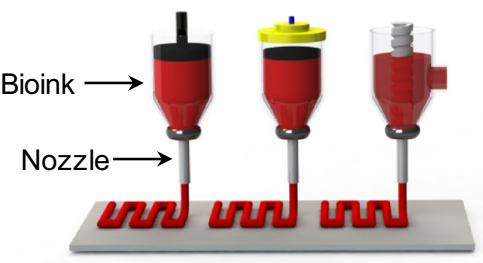

(b)
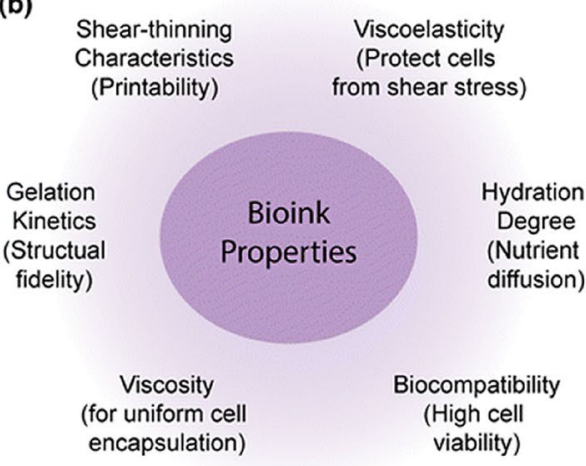

Fig. 8 Bioink properties for
successful 3D bioprinting require a suitable, a biofabrication window which balances printability and biocompatibility whilst providing a variety of (b) suitable rheological, mechanical, and biological characteristics. Image from [157] block the printing nozzle, require high deposition force, and restrict cell attachment and spreading which can negatively impact cell viability [155, 156].

Multiple bioprinting-based strategies have been proposed to generate hierarchical tissue constructs for cartilage applications. One of the early proposed strategies involved the extrusion bioprinting of cell-laden hydrogel bioinks to directly produce 3D cellularised constructs stimulating cartilage formation [158]. Despite promising outcomes, a major drawback of hydrogel constructs relies on the disparity of mechanical properties compared to the native cartilage. To overcome this issue, researchers have combined melt extrusion or melt-electrospinning writing of thermoplastic polymers such as PCL with extrusion bioprinting of cell-laden hydrogel bioinks towards the fabrication of reinforced 3D constructs with improved mechanical performance (Fig. 9). This concept was explored by Visser et al. [118], who reinforced chondrocyte-loaded hydrogels with direct writing of melt-electrospun PCL microfibres achieving up to 54-fold increase in the stiffness of composite constructs when compared with the hydrogel alone constructs. A similar approach was reported by Kang et al. [159] using an integrated tissue-organ printer (ITOP) to generate 3D constructs for cartilage reconstruction via the sequential melt extrusion of PCL strands and the extrusion bioprinting of chondrocyte-laden hydrogels. In another study, Mekhileri et al. [119] proposed a hybrid biofabrication approach combining alternating melt extrusion of a thermoplastic polymer (poly(ethylene glycol)-terephthalate-poly(butylene terephthalate) block copolymers) and microfluidic bioassembly of pre-formed cellular spheroid modules to create hierarchical constructs for cartilage tissue engineering. These examples clearly illustrate that the synergy between different biofabrication technologies holds tremendous promising in create truly biomimetic $3 \mathrm{D}$ constructs able to surpass the limitations of individual technologies/strategies. 


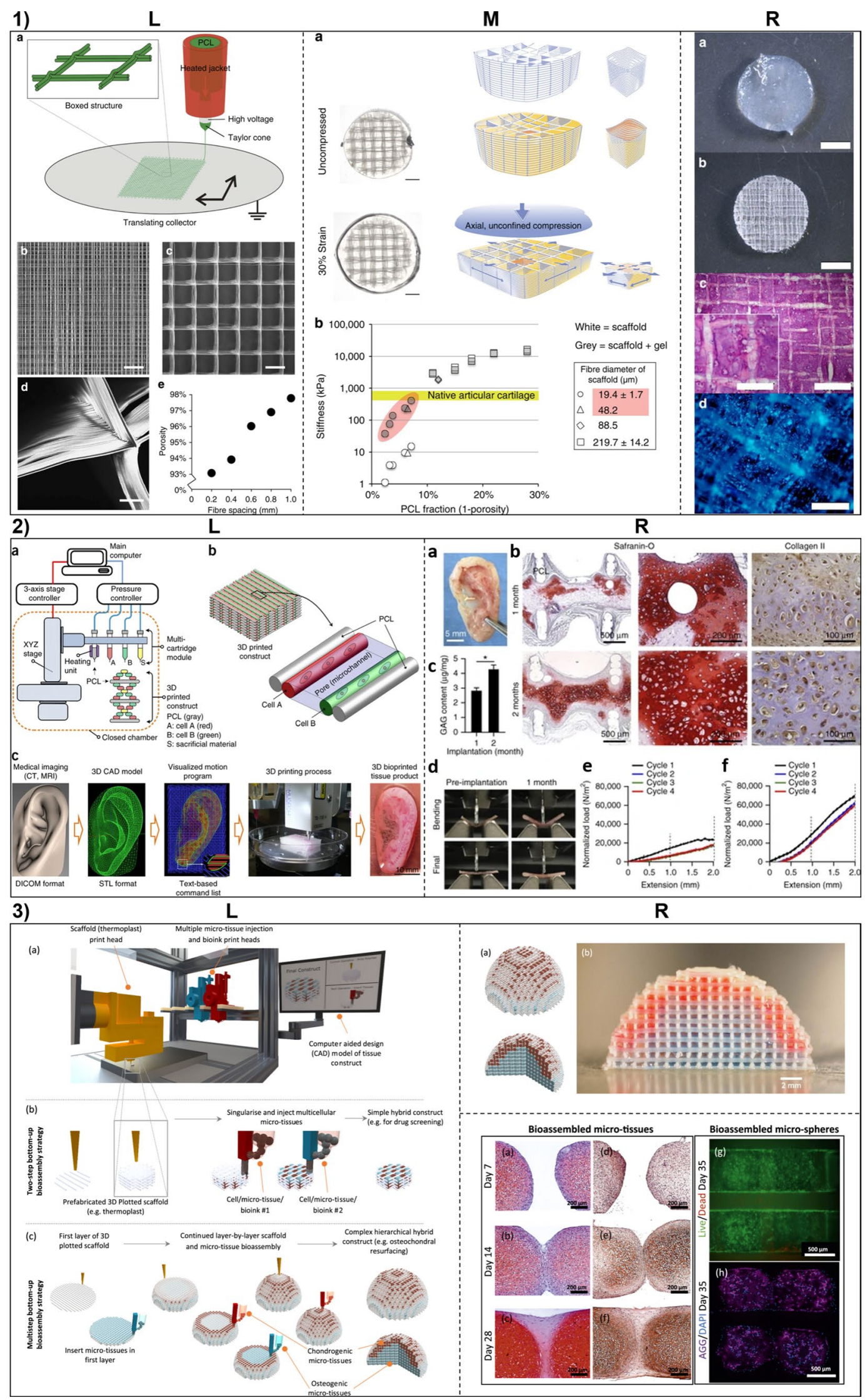


४Fig. 9 Bioprinting hybrid cell-laden scaffolds. (1) Hydrogels reinforced with direct writing of melt-electrospun microfibres. L: a Schematic of the melt-electrospinning system. b, c Fibre deposition and spacing can be precisely controlled (scale $=1 \mathrm{~mm}$ ) with d fused fibres at the cross-sections (scale $=200 \mu \mathrm{m}$ ) and e highly porous structures fabricated. M: a Microfibres reinforce the hydrogel during axial compression and stretch with lateral displacement ( cale $=1 \mathrm{~mm}$ ) enabling a similar, b stiffness to articular cartilage tissue. R: Chondrocytes encapsulated in $\mathbf{a}$ unreinforced and $\mathbf{b}$ reinforced hydrogels (scale bar $=2 \mathrm{~mm}$ ) demonstrate, $\mathbf{c}$ rounded morphology (scale $=500 \mu \mathrm{m}$, inlay $200 \mu \mathrm{m}$, and $\mathbf{d}$ homogenous distribution $($ scale $=200 \mu \mathrm{m})$. Images adapted from [118]. (2) Integrated tissueorgan printer. L: a Schematic of the multi-printhead 3D bioprinting system and $\mathbf{b}$ the basic patterning of cell-laden hydrogels and supporting thermoplastic polymers. c Design and biofabrication process of the system. R: a 3D bioprinting of cell-laden hydrogels and PCL with integrated microchannels. a Gross appearance, b histological staining, and $\mathbf{c}$ GAG production after 1- and 2-month in vivo implantation. d Bending mechanics and stress-strain curves, e before and f after 1-month implantation. Images adapted from [159]. (3) Automated 3D microfluidic bioassembly of cellular spheroids and hybrid constructs. L: a Representation of the 3D bioprinting and bioassembly system. b Two-step bottom-up strategy involving 3D printing a scaffold and subsequently injecting microtissues whilst a (c) multi-step process uses an alternating layer-by-layer process. $\mathrm{R}$ (top): a Computer-aided-design model and $\mathbf{b}$ example of a hybrid biphasic osteochondral construct. R(bottom): a-f Bioassembled microtissues and $\mathbf{g}$, $\mathbf{h}$ micro-spheres demonstrate chondrogenic markers (a-c: safranin-O, $\mathbf{d}-\mathbf{f}$ : collagen II, and $\mathbf{h}$ : aggrecan) and cell viability. Images from [119]

\section{Biochemical and biomechanical stimulation}

Biochemical, biophysical, and biomechanical stimulation of 3D bioengineered constructs is crucial in the formation and maturation of functional neocartilage tissue (Fig. 10). The stimulation of cells can be achieved at specific stages: cell expansion, differentiation, and the maturation of the tissue construct in vitro. This can be attained through supplementation of the cell culture media, incorporation of biomolecules within the 3D structure, engineering the biophysical ECM environment, and mechanical stimulation of the construct.

A key approach to direct cell behaviour and facilitation of neocartilage tissue formation is the use of biological signalling molecules (e.g. growth and transcription factors) during cell culture, tissue maturation, and utilisation via direct inclusion, encapsulation or binding to the biomaterial matrix of the construct [10,160-164]. A range of growth and transcription factors have been identified and investigated including transforming growth factors (TGFs), bone morphogenetic proteins (BMPs), insulin growth factors (IGFs), fibroblastic growth factors (FGFs), platelet-derived growth factors (PDGFs), and sex determining region Y (SRY)-box (SOXs).

Growth factors are proteins that have a key role in cell behaviour and regulate cellular growth, proliferation, differentiation, and migration and are grouped into families with shared amino acid sequences and superfamilies with shared structural folds [161, 162].

In articular cartilage tissue engineering, 3D engineered constructs have been used to deliver these biological factors $[162,165]$. For instance, TGF- $\beta 1$ stimulates the synthesis of cartilage ECM, maintenance of chondrocyte phenotype, synthesis of proteoglycans, aggrecan and type II collagen and can enhance the repair of cartilage defects $[166,167]$. IGF-1 has been reported showing high anabolic effects and decrease in catabolic responses in articular cartilage metabolism in vitro $[167,168]$. Other studies have reported using different growth factors which were successful in producing several features that resembled typical articular cartilage [169-171]. Despite the capacity to promote cartilage matrix formation, growth factors have shown some drawbacks with IGF-1 associated with a loss of chondrocyte phenotype and extracellular matrix breakdown [168]. Furthermore, IGF-1 in human MSCs inhibited collagen II expression and overexpression can induce hypertrophic differentiation and mineralisation [172].

Biomechanical stimulation is a key factor in the development and homeostasis of functional cartilage tissue [173-177]. The importance of mechanical loading and physical movement on embryonic chondrogenesis has been demonstrated in chicken embryos which when physically impaired exhibited poor development of cartilage tissue [178-180]. Mechanical loading is required for healthy tissue, however, excessive loading can lead to trauma and disease progression [173]. Thus, mechanical stimulation of cells and tissue constructs via compression, shear and hydrostatic pressure is important to promote chondrogenic differentiation, maintain a chondrogenic phenotype, and generation of functional tissue in vivo. Mechanical stimulation of MSCs under varied loading regimes have been shown to increase the deposition and expression of collagen II, aggrecan, GAG, TGF- $\beta 1 / \beta 3$, and SOX 9 and modulated secretory factors such as stromal-derived factor-1 (SDF-1), matrix metalloproteinase-2 (MMP-2), TGF- $\beta 1 / \beta 3$, FGF, vascular endothelial growth factor (VEGF), activated leukocyte cell adhesion molecule (ALCAM), nitric oxide, urokinase receptor (UPAR), macrophage inflammatory protein $3 \alpha$ (MIP3 $\alpha$ ). The advancement of bioreactors in tissue engineering has enabled the use of mechanical stimulation as a key capability in engineering cartilage tissue formation [181-183]. Dual compressive and shear mechanical stimulation of human articular chondrocytes encapsulated in gelatin methacrylate and hyaluronic acid methacrylate hydrogels have been demonstrated by Meinert et al. [184]. Cartilage specific marker genes and ECM were upregulated with significant increases in collagen II synthesis. Combining compressive and shear stimulation has been investigated using a multi-axial loading bioreactor which mimics the movement of an articulating joint $[185,186]$. Vainieri et al. investigated a chondrocyte 


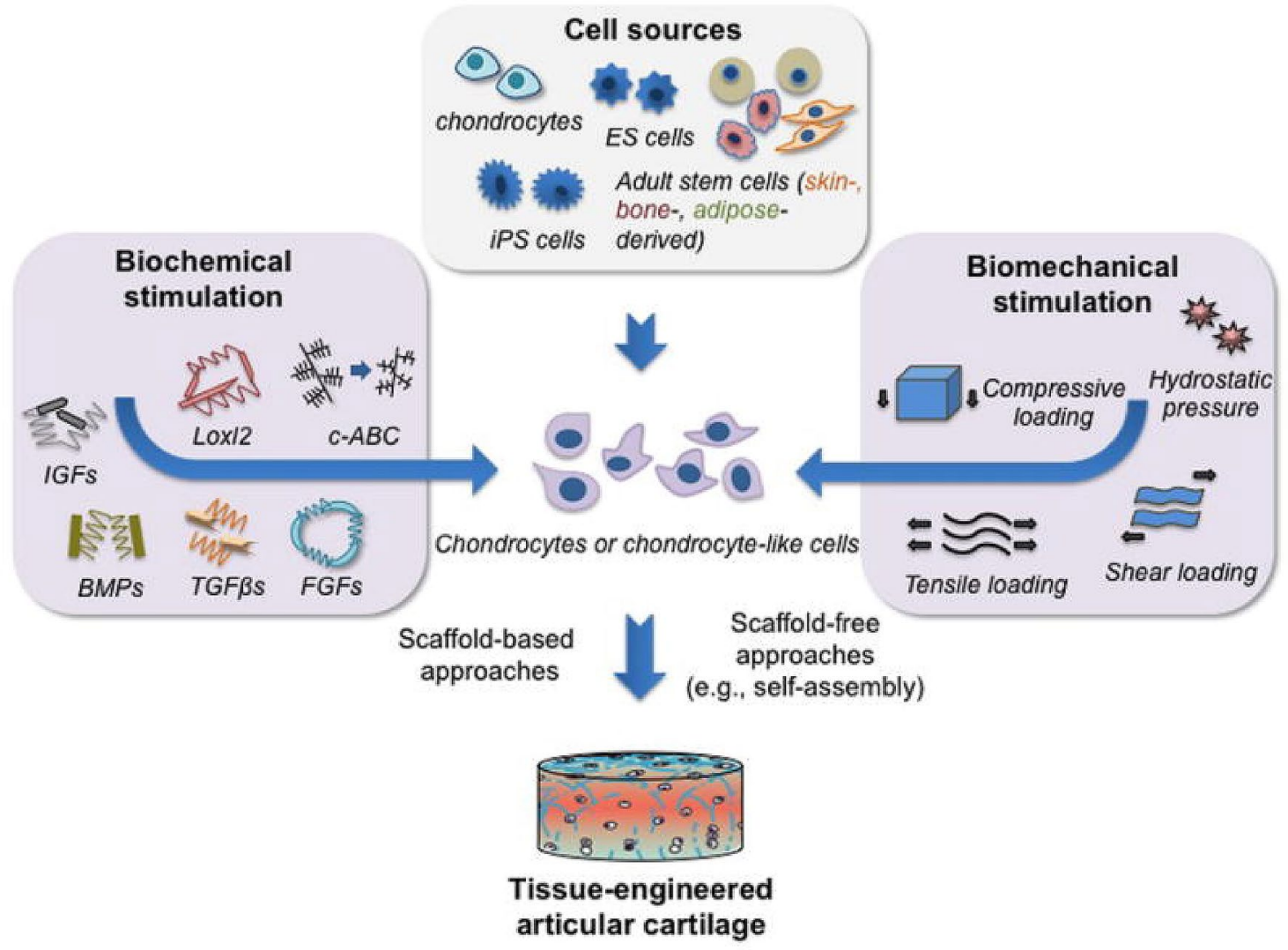

Fig. 10 Biochemical and biomechanical stimulation combined with appropriate cell sources can be used to engineer cartilage tissue constructs. Image from [160]

seeded hybrid fibrin-polyurethane scaffold implanted in a osteochondral defect model that was mechanically stimulated using a joint mimicking bioreactor [186]. The results showed increased production of chondrogenic specific markers, proteoglycan 4 and cartilage oligomeric matrix protein, and the improved collagen II to I ratio. Alternatively, tensile stimulation of a self-assembled scaffold-free neocartilage construct has shown to increase the tensile strength and modulus of the construct and once implanted in vivo in a mice model had similar mechanical properties and collagen content of native tissue [187]. The development of improved mechanically stimulating bioreactors and osteochondral models will provide a valuable tool in understanding cartilage development and will aid the screening of biomaterials and tissue engineering strategies.

\section{Challenges and future perspectives}

Major barriers remain in the development of clinically effective therapies for articular cartilage and osteochondral tissue. These challenges stem for the complexity of the native tissue and the difficulty in guiding regenerative processes while halting degenerative pathologies. This section briefly summarises key challenges identified associated with stimulatory factors, tissue inflammation, and implant-native tissue integration.

Challenges remain in the use of stimulatory processes to guide cell behaviour and tissue development. A complete understanding of chondrogenic development is still being unravelled so the entire milieu of factors that influence tissue formation and their functional spatiotemporal presentation to the cells is incomplete. However, tissue engineering strategies will most likely, to be successful, use a combination of growth factors, a controlled biophysical environment, and mechanical stimulation to promote tissue formation with phenotypic stability. This is supported by the fact that the use of stem cells and chondrocytes, derived or implanted into an osteoarthritic environment, in vitro or in vivo typically results in phenotypic instability and the expression of a hypertrophic chondrocyte phenotype [66, 188, 189]. Biomolecules which can inhibit hypertrophic differentiation have been identified such as parathyroid hormone related peptide, BMP-7, SOX-5/6/9, and Nkx3.2 (transcription factor) thus potentially providing a route to address this issue [190-194]. However, the osteoarthritic joint environment, a main clinical target, presents an obstacle as the disease itself presents a 
degraded and complex growth factor/cytokine environment. This can contribute to induce a hypertrophic phenotype in chondrocytes which may have significant implications for the development of functional implanted tissue constructs $[66,189]$. This will require further understanding of the specific disease state and how different states affect the success of the tissue engineering approach used. The sole use of soluble factors in the maintenance and differentiation of chondrocytes and MSCs in vitro and in vivo seems unlikely to achieve the desired results. Rather the design of these stimulatory environments including biochemical, physical, and mechanical elements will aim to recapitulate the native environment during all developmental stages of the tissue. A successful strategy will need to determine the combination, dosage, and delivery profile of growth factors, as well as the design of the physical matrix surrounding the cells by controlling parameters such as crosslinking density, ECM protein selection, and oxygen tension. Finally, determining the timing, type, and loading conditions of mechanical stimulation will be essential in promoting an ECM which is mechanically compliant. However, the complexity of this environment and the actual implementation of a multistimulatory strategy is a serious challenge for researchers.

The considerable inflammatory environment of osteochondral tissue in a diseased (e.g. osteoarthritis and rheumatoid arthritis) or trauma state presents a significant obstacle for successful clinical outcomes of tissue engineered constructs, hindering tissue-construct integration and tissue regeneration (Fig. 11a) [69, 195-201]. Thus, approaches are necessary to control and understand the inflammatory state which contributes to tissue degradation in osteoarthritic diseases and the influence on implanted tissue constructs. Pro-inflammatory cytokines (e.g. interleukin-1 $1 / /-6$ and tumour necrosis factor- $\alpha$ ) have been implicated in the development of cartilage degradation in osteoarthritic joints and activation of the nuclear factor kappa B pathway; which can also contribute to the inhibition of chondrogenesis in human MSCs [195, 197, 198, 200-203]. Subsequently, understanding and modulating the inflammatory environment is key and has been investigated through a range of approaches including co-cultured adipose-derived MSCs [204], growth factors [165, 195, 196], platelet-rich plasma [205-208], control of macrophage phenotype [209-211], inhibition of anti-chondrogenic factors [212], and inflammation modulating biomaterials [213, 214].

Integration of tissue constructs with the surrounding native tissue, be that cartilage or subchondral bone, is a key challenge. The issue of integration is a complex problem and can be caused be factors including lack of vascularisation, cell donor age, cell death during surgery and construct implantation, cell phenotype, and stage of tissue maturation of the construct [215]. This is further compounded by the anti-adhesive properties of proteoglycans and GAGs present in the native matrix which are essential for proper functioning but can prevent integration. To overcome this issue, enzymatic degradation (e.g. trypsin and chondroitinase$\mathrm{ABC}$ ) of the tissue interface has been explored to temporarily reduce proteoglycan and GAG content to facilitate tissue integration (Fig. 11b) [216-219]. Furthermore, the native ECM can impede diffusion of proteins and cells, thus, disrupting the ECM at the site of implantation by using collagenase and hyaluronidase can enhance cell density and
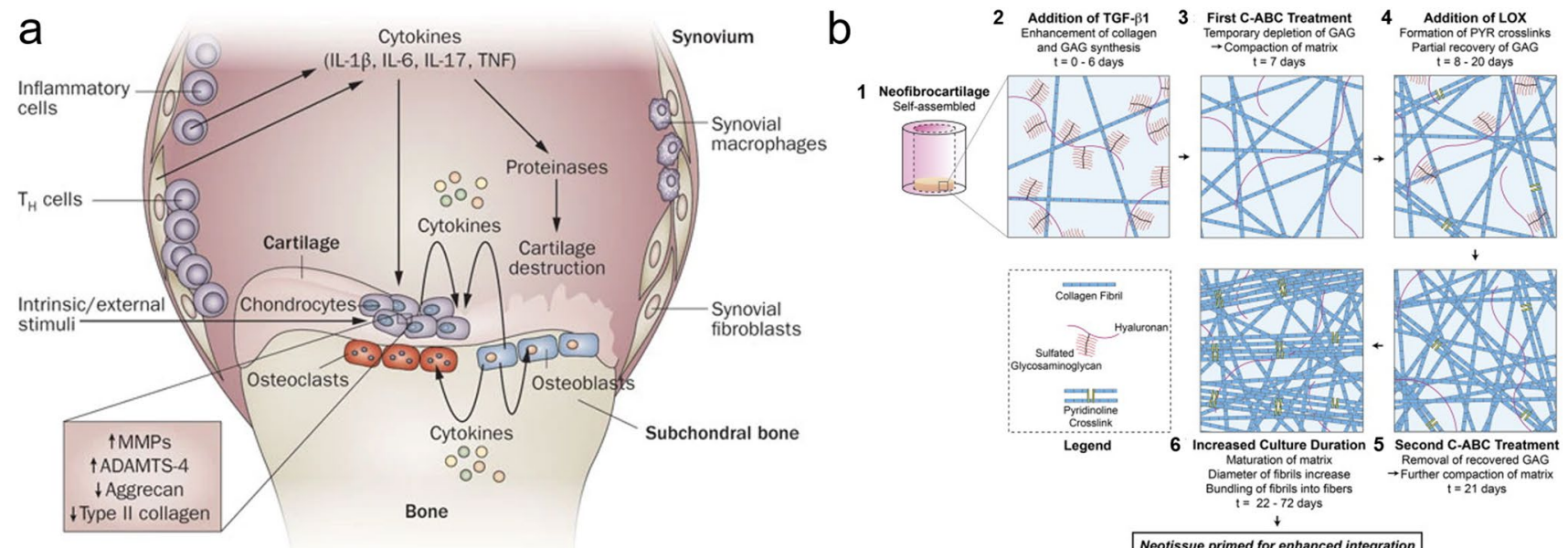

with native tissue at $t=42$ days

Fig. 11 a Complex pro-inflammatory cytokine environment in osteoarthritis leads to upregulation of catabolic and downregulation of anabolic processes resulting in tissue degradation. Cartilage degradation products and pro-inflammatory signals act on the synovium inducing further inflammatory processes that enhances the deregulation of typ- ical chondrocyte function. Image from [200]. b Strategy to enhance implant integration with native cartilage tissue using a combination of chondroitinase-ABC, TGF- $\beta 1$, and collagen crosslinking enzyme LOX. Image from [219]. 
integration [220]. Collagen crosslinking between the native cartilage and tissue construct can be encouraged by minimising complete crosslinking of the construct by blocking the enzyme lysyl oxidase (LOX) subsequently increasing the availability of collagen precursor crosslinking sites to enhance integration. Correspondingly, the construct-native tissue interface can be treated with LOX to enhance and mature collagen crosslinking via collagen pyridinoline crosslinks that can anchor and bridge the interface [219, 221]. However, implant integration can be influenced by the post-surgery recovery plan, thus appropriate rehabilitation regimes need to be followed. Furthermore, development of surgical procedures to secure implants in place during the integration and maturation phase are required. For example, Vapniarsky et al. have demonstrated a new technique which does not require suturing of the implant [222].

\section{Concluding remarks}

The clinical size and market of cartilage and osteochondral problems is expanding due to the ageing worldwide population and the most common treatment approaches are ineffective at halting the progression of degeneration of the tissue $[65,66,69]$. Thus, tissue engineering strategies are key in solving this pressing clinical problem. The design specification of any biomaterial-based 3D construct must fulfil a stringent criterion requiring suitable biomaterial selection, scaffold architecture, fabrication technique, stimulatory factors, and tissue maturation.

Key areas of research include the maintenance of phenotype in the engineered tissue construct and the prevention of hypertrophic or fibrocartilage phenotypes being expressed. Expansion of therapeutic cells in vitro to sufficient quantities for clinical applications whilst maintaining cell phenotype is a key challenge and research goal. The number of autologous chondrocytes that can be harvested is limited and subsequent passaging rapidly induces phenotypic changes. Thus, the development of in vitro culturing processes that maintain chondrocyte phenotype and guide chondrogenic development of alternative cell sources. Allogenic cells are an attractive source as articular cartilage is typically considered immune-privileged due to its avascular nature thus allowing the use of allografts. However, this is dependent on implant location within the joint and proximity to the synovium consequently this needs to be taken into consideration when developing tissue engineering therapies [223].

Another important issue concerns to the development of more effective strategies to promote the integration of tissue constructs with the host healthy tissue in an osteochondral defect, although in total replacement the strategy would primarily to be to anchor the neocartilage to underlying bone. Furthermore, the underlying biological behaviour of the tissue, the early-stage developmental biology, haemostatic processes in adult tissue, and the inflammatory environment in osteoarthritic joints need further understanding.

This knowledge may unlock key aspects of the tissue which may guide tissue engineering strategies. This could require a strategy of multiple stimulatory factors (e.g. growth factors and mechanical stimulation) over an extended maturation time of up to many years to mimic the underlying biological development of the tissue and even then, the incorporation of permanent mechanical structures may be necessary. Subsequently, future studies should focus on a multi-stimulatory environment, long-term studies to determine phenotypic alterations and tissue formation, and the development of novel bioreactor systems that can more accurately resemble the in vivo environment. Furthermore, novel approaches utilising gene therapy combined with tissue engineering scaffolds are also a promising approach which may offer a route to solving intractable issues surrounding articular cartilage degeneration [224, 225]. Finally, a clear and considered route in the development process of the materials, structures, and strategy should be evaluated prior and during the research phase to expediate clinical and regulatory approval. This will allow faster and more successful access to animal trials and eventually human clinical trials with the prospect of an efficacious therapy being developed.

Acknowledgements The authors wish to acknowledge the funding provided by the Engineering and Physical Sciences Research Council (EPSRC) and Medical Research Council (MRC) Centre for Doctoral Training in Regenerative Medicine (EP/L014904/1), support of the government of Iraq through a grant provided by the Higher Committee for Development Education Iraq (HCED), and R.F. Pereira was supported by the project PTDC/MEC-GIN/29232/2017 and the Institute of Network Bioengineering for Healthy Aging (0245_IBEROS_1_E).

\section{Compliance with ethical standards}

Conflict of interest On behalf of all authors, the corresponding author states that there is no conflict of interest.

Open Access This article is licensed under a Creative Commons Attribution 4.0 International License, which permits use, sharing, adaptation, distribution and reproduction in any medium or format, as long as you give appropriate credit to the original author(s) and the source, provide a link to the Creative Commons licence, and indicate if changes were made. The images or other third party material in this article are included in the article's Creative Commons licence, unless indicated otherwise in a credit line to the material. If material is not included in the article's Creative Commons licence and your intended use is not permitted by statutory regulation or exceeds the permitted use, you will need to obtain permission directly from the copyright holder. To view a copy of this licence, visit http://creativecommons.org/licenses/by/4.0/. 


\section{References}

1. Madry H, van Dijk CN, Mueller-Gerbl M (2010) The basic science of the subchondral bone. Knee Surg Sports Traumatol Arthrosc 18(4):419-433

2. Lin Z, Willers C, Xu J, Zheng M-H (2006) The chondrocyte: biology and clinical application. Tissue Eng 12(7):1971-1984. https://doi.org/10.1089/ten.2006.12.1971

3. Duarte Campos DF, Drescher W, Rath B, Tingart M, Fischer H (2012) Supporting biomaterials for articular cartilage repair. Cartilage 3(3):205-221

4. Mankin HJ (1982) The response of articular cartilage to mechanical injury. JBJS 64(3):460-466

5. Szafranski JD, Grodzinsky AJ, Burger E, Gaschen V, Hung H-H, Hunziker EB (2004) Chondrocyte mechanotransduction: effects of compression on deformation of intracellular organelles and relevance to cellular biosynthesis. Osteoarth Cartilage 12(12):937-946

6. Sophia Fox AJ, Bedi A, Rodeo SA (2009) The basic science of articular cartilage: structure, composition, and function. Sports Health 1(6):461-468

7. Camarero-Espinosa S, Rothen-Rutishauser B, Foster EJ, Weder C (2016) Articular cartilage: from formation to tissue engineering. Biomater Sci 4(5):734-767

8. Poole C (1997) Articular cartilage chondrons: form, function and failure. J Anat 1997(191):1-13

9. Huey DJ, Hu JC, Athanasiou KA (2012) Unlike bone, cartilage regeneration remains elusive. Science 338(6109):917-921

10. Kwon H, Brown WE, Lee CA, Wang D, Paschos N, Hu JC et al (2019) Surgical and tissue engineering strategies for articular cartilage and meniscus repair. Nat Rev Rheumatol 15(9):550-570

11. Balakrishnan B, Banerjee R (2011) Biopolymer-based hydrogels for cartilage tissue engineering. Chem Rev 111(8):4453-4474

12. Makris EA, Gomoll AH, Malizos KN, Hu JC, Athanasiou KA (2015) Repair and tissue engineering techniques for articular cartilage. Nat Rev Rheumatol 11:21

13. Huang BJ, Hu JC, Athanasiou KA (2016) Cell-based tissue engineering strategies used in the clinical repair of articular cartilage. Biomaterials 98:1-22

14. Melchels FPW, Domingos MAN, Klein TJ, Malda J, Bartolo PJ, Hutmacher DW (2012) Additive manufacturing of tissues and organs. Prog Polym Sci 37(8):1079-1104

15. Vyas C, Poologasundarampillai G, Hoyland J, Bartolo P (2017) $3 \mathrm{D}$ printing of biocomposites for osteochondral tissue engineering. In: Ambrosio L (ed) Biomedical Composites, 2nd edn. Woodhead Publishing, Sawston, pp 261-302

16. Murphy SV, Atala A (2014) 3D bioprinting of tissues and organs. Nat Biotechnol 32:773

17. Morgan FLC, Moroni L, Baker MB (2020) Dynamic bioinks to advance bioprinting. Adv Healthc Mater. https://doi.org/10.1002/ adhm.201901798

18. Malda J, Groll J, van Weeren PR (2019) Rethinking articular cartilage regeneration based on a 250 -year-old statement. Nat Rev Rheumatol 15(10):571-572. https://doi.org/10.1038/s4158 4-019-0278-7

19. Benjamin M, Evans EJ (1990) Fibrocartilage. J Anat 171:1

20. Bhosale AM, Richardson JB (2008) Articular cartilage: structure, injuries and review of management. Br Med Bull 87(1):77-95

21. Poole AR, Kojima T, Yasuda T, Mwale F, Kobayashi M, Laverty S (2001) Composition and structure of articular cartilage: a template for tissue repair. Clin Orthop Relat Res 391:S26-S33

22. Eyre D (2001) Articular cartilage and changes in arthritis: collagen of articular cartilage. Arth Res Ther 4(1):30

23. Basser PJ, Schneiderman R, Bank RA, Wachtel E, Maroudas A (1998) Mechanical properties of the collagen network in human articular cartilage as measured by osmotic stress technique. Arch Biochem Biophys 351(2):207-219

24. Cancedda R (2009) Cartilage and bone extracellular matrix. Curr Pharm Des 15(12):1334-1348

25. Lipshitz H, Glimcher MJ (1975) In vitro wear of articular cartilage. J Bone Joint Surg Am Volume 57(4):527-534

26. Temenoff JS, Mikos AG (2000) Review: tissue engineering for regeneration of articular cartilage. Biomaterials 21(5):431-440

27. Roughley PJ (2006) The structure and function of cartilage proteoglycans. Eur Cell Mater 12:92-101. https://doi.org/10.22203 /ecm.v012a11

28. Eyre DR, Wu JJ (1983) Collagen of fibrocartilage: a distinctive molecular phenotype in bovine meniscus. FEBS Lett 158(2):265-270

29. Marlovits S, Hombauer M, Truppe M, Vècsei V, Schlegel W (2004) Changes in the ratio of type-I and type-II collagen expression during monolayer culture of human chondrocytes. J Bone Joint Surg Br Volume 86-B(2):286-295

30. Schnabel M, Marlovits S, Eckhoff G, Fichtel I, Gotzen L, Vecsei $V$ et al (2002) Dedifferentiation-associated changes in morphology and gene expression in primary human articular chondrocytes in cell culture. Osteoarth Cartilage 10(1):62-70

31. Eyre DR, Wu J-J (2005) Collagen cross-links. In: Brinckmann J, Notbohm H, Müller PK (eds) Collagen: primer in structure, processing and assembly. Springer, Berlin, pp 207-229

32. Luo Y, Sinkeviciute D, He Y, Karsdal M, Henrotin Y, Mobasheri A et al (2017) The minor collagens in articular cartilage. Protein Cell 8(8):560-572

33. Karl K (2004) Matrix loading: assembly of extracellular matrix collagen fibrils during embryogenesis. Birth Defects Res Part C 72(1):1-11

34. Changoor A, Nelea M, Méthot S, Tran-Khanh N, Chevrier A, Restrepo A et al (2011) Structural characteristics of the collagen network in human normal, degraded and repair articular cartilages observed in polarized light and scanning electron microscopies. Osteoarth Cartilage 19(12):1458-1468

35. Thambyah A, Broom N (2007) On how degeneration influences load-bearing in the cartilage-bone system: a microstructural and micromechanical study. Osteoarth Cartilage 15(12):1410-1423

36. Lindahl A (2015) From gristle to chondrocyte transplantation: treatment of cartilage injuries. Philos Trans R Soc B 370(1680):20140369

37. Maroudas A, Muir H, Wingham J (1969) The correlation of fixed negative charge with glycosaminoglycan content of human articular cartilage. Biochimica et Biophysica Acta (BBA) 177(3):492-500

38. Lorenzo P, Bayliss MT, Heinegårdt D (1998) A novel cartilage protein (CILP) present in the mid-zone of human articular cartilage increases with age. J Biol Chem 273(36):23463-23468

39. Perrimon N, Bernfield M (eds) (2001) Cellular functions of proteoglycans - an overview. Academic Press, Cambridge

40. Venn M, Maroudas A (1977) Chemical composition and swelling of normal and osteoarthrotic femoral head cartilage. I. Chemical composition. Ann Rheum Dis 36(2):121-129

41. Holopainen JT, Brama PAJ, Halmesmaki E, Harjula T, Tuukkanen J, van Weeren PR et al (2008) Changes in subchondral bone mineral density and collagen matrix organization in growing horses. Bone 43(6):1108-1114

42. Castaneda S, Roman-Blas JA, Largo R, Herrero-Beaumont G, Castañeda S, Roman-Blas JA et al (2012) Subchondral bone as a key target for osteoarthritis treatment. Biochem Pharmacol 83(3):315-323

43. Schinagl RM, Gurskis D, Chen AC, Sah RL (1997) Depthdependent confined compression modulus of full-thickness bovine articular cartilage. J Orthop Res 15(4):499-506 
44. Nguyen LH, Kudva AK, Saxena NS, Roy K (2011) Engineering articular cartilage with spatially-varying matrix composition and mechanical properties from a single stem cell population using a multi-layered hydrogel. Biomaterials 32(29):6946-6952

45. Kumar P, Oka M, Toguchida J, Kobayashi M, Uchida E, Nakamura $T$ et al (2001) Role of uppermost superficial surface layer of articular cartilage in the lubrication mechanism of joints. $\mathrm{J}$ Anat 199(3):241-250

46. Gudas R, Gudaitè A, Mickevičius T, Masiulis N, Simonaitytė R, Čekanauskas E et al (2013) Comparison of osteochondral autologous transplantation, microfracture, or debridement techniques in articular cartilage lesions associated with anterior cruciate ligament injury: a prospective study with a 3-year follow-up. Arthroscopy 29(1):89-97

47. Goyal D, Keyhani S, Lee EH, Hui JHP (2013) Evidence-based status of microfracture technique: a systematic review of level I and II studies. Arthroscopy 29(9):1579-1588

48. Steadman JR, Briggs KK, Rodrigo JJ, Kocher MS, Gill TJ, Rodkey WG (2003) Outcomes of microfracture for traumatic chondral defects of the knee: average 11-year follow-up. Arthroscopy 19(5):477-484

49. Kreuz PC, Steinwachs MR, Erggelet C, Krause SJ, Konrad G, Uhl M et al (2006) Results after microfracture of full-thickness chondral defects in different compartments in the knee. Osteoarth Cartilage 14(11):1119-1125

50. Correia CR, Reis RL, Mano JF (2015) Multiphasic, multistructured and hierarchical strategies for cartilage regeneration. In: Bertassoni LE, Coelho PG, editors. Cham: Springer International Publishing, pp 143-60

51. Dorotka R, Windberger U, Macfelda K, Bindreiter U, Toma C, Nehrer S (2005) Repair of articular cartilage defects treated by microfracture and a three-dimensional collagen matrix. Biomaterials 26(17):3617-3629

52. Nukavarapu SP, Dorcemus DL (2013) Osteochondral tissue engineering: current strategies and challenges. Biotechnol Adv 31(5):706-721

53. Yousefi AM, Hoque ME, Prasad RG, Uth N (2015) Current strategies in multiphasic scaffold design for osteochondral tissue engineering: a review. J Biomed Mater Res Part A 103(7):2460-2481

54. Peterson L, Minas T, Brittberg M, Nilsson A, Sjögren-Jansson E, Lindahl A (2000) Two- to 9-year outcome after autologous chondrocyte transplantation of the knee. Clin Orthop Relat Res (1976-2007) 374:212-234

55. Gomoll AH, Probst C, Farr J, Cole BJ, Minas T (2009) Use of a type I/III bilayer collagen membrane decreases reoperation rates for symptomatic hypertrophy after autologous chondrocyte implantation. Am J Sports Med 37(1_suppl):20-23

56. Darling EM, Athanasiou KA (2005) Rapid phenotypic changes in passaged articular chondrocyte subpopulations. J Orthop Res 23(2):425-432

57. Martinez I, Elvenes J, Olsen R, Bertheussen K, Johansen O (2008) Redifferentiation of in vitro expanded adult articular chondrocytes by combining the hanging-drop cultivation method with hypoxic environment. Cell Transplant 17(8):987-996

58. Caron MMJ, Emans PJ, Coolsen MME, Voss L, Surtel DAM, Cremers A et al (2012) Redifferentiation of dedifferentiated human articular chondrocytes: comparison of $2 \mathrm{D}$ and $3 \mathrm{D}$ cultures. Osteoarth Cartilage 20(10):1170-1178

59. Demange M, Gomoll AH (2012) The use of osteochondral allografts in the management of cartilage defects. Curr Rev Musculoskelet Med 5(3):229-235

60. Krych AJ, Harnly HW, Rodeo SA, Williams RJ III (2012) Activity levels are higher after osteochondral autograft transfer mosaicplasty than after microfracture for articular cartilage defects of the knee: a retrospective comparative study. JBJS 94(11):971-978

61. Gudas R, Kalesinskas RJ, Kimtys V, Stankevičius E, Toliušis V, Bernotavičius $\mathrm{G}$ et al (2005) A prospective randomized clinical study of mosaic osteochondral autologous transplantation versus microfracture for the treatment of osteochondral defects in the knee joint in young athletes. Arthroscopy 21(9):1066-1075

62. Bentley G, Biant LC, Vijayan S, Macmull S, Skinner JA, Carrington RWJ (2012) Minimum ten-year results of a prospective randomised study of autologous chondrocyte implantation versus mosaicplasty for symptomatic articular cartilage lesions of the knee. J Bone Joint Surg Br Volume 94-B(4):504-509

63. Lee WY-W, Wang B (2017) Cartilage repair by mesenchymal stem cells: Clinical trial update and perspectives. J Orthop Trans 9:76-88

64. Jeon OH, Kim C, Laberge R-M, Demaria M, Rathod S, Vasserot AP et al (2017) Local clearance of senescent cells attenuates the development of post-traumatic osteoarthritis and creates a proregenerative environment. Nat Med 23(6):775-781

65. Glyn-Jones S, Palmer AJR, Agricola R, Price AJ, Vincent TL, Weinans $\mathrm{H}$ et al (2015) Osteoarthritis. The Lancet 386(9991):376-387

66. Hunter DJ, Bierma-Zeinstra S (2019) Osteoarthritis. The Lancet 393(10182):1745-1759

67. McCarthy JC, Noble PC, Schuck MR, Wright J, Lee J (2001) The role of labral lesions to development of early degenerative hip disease. Clin Orthop Relat Res 393:25-37

68. Felson DT, Lawrence RC, Dieppe PA, Hirsch R, Helmick CG, Jordan JM et al (2000) Osteoarthritis: new insights. Part 1: the disease and its risk factors. Ann Intern Med 133(8):635-646

69. Martel-Pelletier J, Barr AJ, Cicuttini FM, Conaghan PG, Cooper C, Goldring MB et al (2016) Osteoarthritis. Nat Rev Dis Primers 2(1): 16072

70. Alford JW, Cole BJ (2005) Cartilage restoration, part 2: techniques, outcomes, and future directions. Am J Sports Med 33(3):443-460

71. Drobnič M, Radosavljevič D, Cör A, Brittberg M, Stražar K (2010) Debridement of cartilage lesions before autologous chondrocyte implantation by open or transarthroscopic techniques. J Bone Joint Surg Br Volume 92-B(4):602-608

72. Steadman JR, Rodkey WG, Rodrigo JJ (2001) Microfracture: surgical technique and rehabilitation to treat chondral defects. Clin Orthop Relat Res 391:S362-S369

73. Steadman JR, Rodkey WG, Singleton SB, Briggs KK (1997) Microfracture technique forfull-thickness chondral defects: technique and clinical results. Oper Tech Orthop 7(4):300-304

74. Spahn G, Kahl E, Mückley T, Hofmann GO, Klinger HM (2008) Arthroscopic knee chondroplasty using a bipolar radiofrequencybased device compared to mechanical shaver: results of a prospective, randomized, controlled study. Knee Surg Sports Traumatol Arthrosc 16(6):565-573

75. Mirza MZ, Swenson RD, Lynch SA (2015) Knee cartilage defect: marrow stimulating techniques. Curr Rev Musculoskelet Med 8(4):451-456

76. Wang L, Lazebnik M, Detamore MS (2009) Hyaline cartilage cells outperform mandibular condylar cartilage cells in a TMJ fibrocartilage tissue engineering application. Osteoarth Cartilage 17(3):346-353

77. Bae DK, Yoon KH, Song SJ (2006) Cartilage healing after microfracture in osteoarthritic knees. Arthroscopy 22(4):367-374

78. Knutsen G, Engebretsen L, Ludvigsen TC, Drogset JO, Grøntvedt T, Solheim E et al (2004) Autologous chondrocyte implantation compared with microfracture in the knee: a randomized trial. JBJS 86(3):455-464

79. Peterson L, Minas T, Brittberg M, Lindahl A (2003) Treatment of osteochondritis dissecans of the knee with autologous 
chondrocyte transplantation: results at two to ten years. JBJS 85(Suppl_2):17-24

80. Lee YHD, Suzer F, Thermann H (2014) Autologous matrixinduced chondrogenesis in the knee: a review. Cartilage 5(3):145-153

81. Volz M, Schaumburger J, Frick H, Grifka J, Anders S (2017) A randomized controlled trial demonstrating sustained benefit of Autologous Matrix-Induced Chondrogenesis over microfracture at five years. Int Orthop 41(4):797-804

82. Gao L, Orth P, Cucchiarini M, Madry H (2017) Autologous matrix-induced chondrogenesis: a systematic review of the clinical evidence. Am J Sports Med 47(1):222-231

83. Cotter EJ, Wang KC, Yanke AB, Chubinskaya S (2018) Bone marrow aspirate concentrate for cartilage defects of the knee: from bench to bedside evidence. Cartilage 9(2):161-170

84. Madry H, Gao L, Eichler H, Orth P, Cucchiarini M (2017) Bone marrow aspirate concentrate-enhanced marrow stimulation of chondral defects. Stem Cells Int 2017:1609685

85. Neubauer M, Jeyakumar V, Muellner T, Nehrer S (2018) Bonemarrow-aspirate-concentrate for chondral defects: surgical techniques, clinical applications and basic science. Ann Joint 3:107

86. Holton J, Imam M, Ward J, Snow M (2016) The basic science of bone marrow aspirate concentrate in chondral injuries. Orthop Rev (Pavia) 8(3):6659

87. Gobbi A, Whyte GP (2019) Long-term clinical outcomes of onestage cartilage repair in the knee with hyaluronic acid-based scaffold embedded with mesenchymal stem cells sourced from bone marrow aspirate concentrate. Am J Sports Med 47(7):1621-1628

88. Gobbi A, Karnatzikos G, Scotti C, Mahajan V, Mazzucco L, Grigolo B (2011) One-step cartilage repair with bone marrow aspirate concentrated cells and collagen matrix in full-thickness knee cartilage lesions: results at 2-year follow-up. Cartilage 2(3):286-299

89. Themistocleous GS, Chloros GD, Kyrantzoulis IM, Georgokostas IA, Themistocleous MS, Papagelopoulos PJ et al (2018) Effectiveness of a single intra-articular bone marrow aspirate concentrate (BMAC) injection in patients with grade 3 and 4 knee osteoarthritis. Heliyon 4(10):e00871

90. Bachmeier CJM, March LM, Cross MJ, Lapsley HM, Tribe KL, Courtenay BG et al (2001) A comparison of outcomes in osteoarthritis patients undergoing total hip and knee replacement surgery. Osteoarth Cartilage 9(2):137-146

91. Sibanda N, Copley LP, Lewsey JD, Borroff M, Gregg P, MacGregor AJ et al (2008) Revision rates after primary hip and knee replacement in England between 2003 and 2006. PLoS Med 5(9):e179-e

92. Park Y-B, Ha C-W, Rhim JH, Lee H-J (2018) Stem cell therapy for articular cartilage repair: review of the entity of cell populations used and the result of the clinical application of each entity. Am J Sports Med 46(10):2540-2552

93. Gobbi A, Nehrer S, Neubauer M, Herman K (2019) Tissue engineering for the cartilage repair of the ankle. In: Canata GL, d'Hooghe P, Hunt KJ, Kerkhoffs GMMJ, Longo UG (eds) Sports injuries of the foot and ankle a focus on advanced surgical techniques. Springer, Berlin, pp 119-124

94. Fuentes-Mera L, Camacho A, Engel E, Pérez-Silos V, LaraArias J, Marino-Martínez I, et al (2019) Therapeutic potential of articular cartilage regeneration using tissue engineering based on multiphase designs. Cartilage Tissue Eng Regen Tech

95. Phull A-R, Eo S-H, Abbas Q, Ahmed M, Kim SJ (2016) Applications of chondrocyte-based cartilage engineering: an overview. Biomed Res Int 2016. https://doi.org/10.1155/2016/1879837

96. Baugé C, Boumédiene K (2015) Use of adult stem cells for cartilage tissue engineering: current status and future developments. Stem Cells Int 2015:438026
97. Fisher JN, Tessaro I, Bertocco T, Peretti GM, Mangiavini L (2017) The application of stem cells from different tissues to cartilage repair. Stem Cells Int 2017:2761678

98. Goldberg A, Mitchell K, Soans J, Kim L, Zaidi R (2017) The use of mesenchymal stem cells for cartilage repair and regeneration: a systematic review. J Orthop Surg Res 12(1):39

99. Castro-Viñuelas R, Sanjurjo-Rodríguez C, Piñeiro-Ramil M, Hermida-Gómez T, Fuentes-Boquete IM, de Toro-Santos FJ et al (2018) Induced pluripotent stem cells for cartilage repair: current status and future perspectives. Eur Cells Mater 36:96-109

100. Guzzo RM, O’Sullivan MB (2016) Human pluripotent stem cells: advances in chondrogenic differentiation and articular cartilage regeneration. Curr Mol Biol Rep 2(3):113-122

101. Toh WS, Lee EH, Cao T (2011) Potential of human embryonic stem cells in cartilage tissue engineering and regenerative medicine. Stem Cell Rev Rep 7(3):544-559

102. James AW, Hindle P, Murray IR, West CC, Tawonsawatruk T, Shen J et al (2017) Pericytes for the treatment of orthopedic conditions. Pharmacol Ther 171:93-103

103. Lee JK, Link JM, Hu JCY, Athanasiou KA (2017) The selfassembling process and applications in tissue engineering. Cold Spring Harbor Perspect Med 7(11):a025668

104. Ovsianikov A, Khademhosseini A, Mironov V (2018) The synergy of scaffold-based and scaffold-free tissue engineering strategies. Trends Biotechnol 36(4):348-357

105. Li L, Yu F, Zheng L, Wang R, Yan W, Wang Z et al (2019) Natural hydrogels for cartilage regeneration: modification, preparation and application. J Orthop Trans 17:26-41

106. Sánchez-Téllez AD, Téllez-Jurado L, Rodríguez-Lorenzo ML (2017) Hydrogels for cartilage regeneration, from polysaccharides to hybrids. Polymers 9(12):671

107. Tchobanian A, Van Oosterwyck H, Fardim P (2019) Polysaccharides for tissue engineering: current landscape and future prospects. Carbohyd Polym 205:601-625

108. Van Den Bulcke AI, Bogdanov B, De Rooze N, Schacht EH, Cornelissen M, Berghmans H (2000) Structural and rheological properties of methacrylamide modified gelatin hydrogels. Biomacromol 1(1):31-38

109. Klotz BJ, Gawlitta D, Rosenberg AJWP, Malda J, Melchels FPW (2016) Gelatin-methacryloyl hydrogels: towards biofabricationbased tissue repair. Trends Biotechnol 34(5):394-407

110. Yue K, Trujillo-de Santiago G, Alvarez MM, Tamayol A, Annabi N, Khademhosseini A (2015) Synthesis, properties, and biomedical applications of gelatin methacryloyl (GelMA) hydrogels. Biomaterials 73:254-271

111. Rodríguez-Vázquez M, Vega-Ruiz B, Ramos-Zúñiga R, SaldañaKoppel DA, Quiñones-Olvera LF (2015) Chitosan and its potential use as a scaffold for tissue engineering in regenerative medicine 2015

112. Raghunath J, Salacinski HJ, Sales KM, Butler PE, Seifalian AM (2005) Advancing cartilage tissue engineering: the application of stem cell technology. Curr Opin Biotechnol 16(5):503-509. https://doi.org/10.1016/j.copbio.2005.08.004

113. Hacker MC, Krieghoff J, Mikos AG (2019) Synthetic polymers. Principles of regenerative medicine. Elsevier, Amsterdam, pp $559-590$

114. Coenen AMJ, Bernaerts KV, Harings JAW, Jockenhoevel S, Ghazanfari S (2018) Elastic materials for tissue engineering applications: natural, synthetic, and hybrid polymers. Acta Biomater 79:60-82

115. Sridhar BV, Brock JL, Silver JS, Leight JL, Randolph MA, Anseth KS (2015) Development of a cellularly degradable PEG hydrogel to promote articular cartilage extracellular matrix deposition. Adv Healthc Mater 4(5):702-713

116. Skaalure SC, Dimson SO, Pennington AM, Bryant SJ (2014) Semi-interpenetrating networks of hyaluronic acid in degradable 
PEG hydrogels for cartilage tissue engineering. Acta Biomater 10(8):3409-3420

117. Boere KWM, Visser J, Seyednejad H, Rahimian S, Gawlitta D, van Steenbergen MJ et al (2014) Covalent attachment of a three-dimensionally printed thermoplast to a gelatin hydrogel for mechanically enhanced cartilage constructs. Acta Biomater 10(6):2602-2611

118. Visser J, Melchels FPW, Jeon JE, van Bussel EM, Kimpton LS, Byrne HM et al (2015) Reinforcement of hydrogels using threedimensionally printed microfibres. Nat Commun 6(1):6933

119. Mekhileri NV, Lim KS, Brown GCJ, Mutreja I, Schon BS, Hooper GJ et al (2018) Automated 3D bioassembly of microtissues for biofabrication of hybrid tissue engineered constructs. Biofabrication 10(2):024103

120. Richardson BM, Wilcox DG, Randolph MA, Anseth KS (2019) Hydrazone covalent adaptable networks modulate extracellular matrix deposition for cartilage tissue engineering. Acta Biomater 83:71-82

121. Sun Y, Yan L, Chen S, Pei M (2018) Functionality of decellularized matrix in cartilage regeneration: a comparison of tissue versus cell sources. Acta Biomater 74:56-73

122. Badylak SF, Freytes DO, Gilbert TW (2009) Extracellular matrix as a biological scaffold material: structure and function. Acta Biomater 5(1):1-13

123. Beachley V, Ma G, Papadimitriou C, Gibson M, Corvelli M, Elisseeff J (2018) Extracellular matrix particle-glycosaminoglycan composite hydrogels for regenerative medicine applications. $\mathbf{J}$ Biomed Mater Res Part A 106(1):147-159

124. Liu X, Meng H, Guo Q, Sun B, Zhang K, Yu W et al (2018) Tissue-derived scaffolds and cells for articular cartilage tissue engineering: characteristics, applications and progress. Cell Tissue Res 372(1):13-22

125. Kim YS, Majid M, Melchiorri AJ, Mikos AG (2018) Applications of decellularized extracellular matrix in bone and cartilage tissue engineering. Bioeng Trans Med 4(1):83-95

126. Kim YS, Majid M, Melchiorri AJ, Mikos AGJB (2019) Medicine t. Applications of decellularized extracellular matrix in bone and cartilage tissue engineering. Bioeng Trans Med 4(1):83-95

127. Benders KEM, Weeren PRV, Badylak SF, Saris DBF, Dhert WJA, Malda J (2013) Extracellular matrix scaffolds for cartilage and bone regeneration. Trends Biotechnol 31(3):169-176

128. Kim YS, Majid M, Melchiorri AJ, Mikos AG (2019) Applications of decellularized extracellular matrix in bone and cartilage tissue engineering. Bioeng Transla Med 4(1):83-95

129. Schwarz S, Koerber L, Elsaesser AF, Goldberg-Bockhorn E, Seitz AM, Durselen L et al (2012) Decellularized cartilage matrix as a novel biomatrix for cartilage tissue-engineering applications. Tissue Eng Part A 18(21-22):2195-2209

130. Benders KE, Terpstra ML, Levato R, Malda JJJ (2019) Fabrication of decellularized cartilage-derived matrix scaffolds. JoVE 143:e58656

131. Benders KEM, Boot W, Cokelaere SM, Van Weeren PR, Gawlitta D, Bergman HJ et al (2014) Multipotent stromal cells outperform chondrocytes on cartilage-derived matrix scaffolds. Cartilage 5(4):221-230

132. Pati F, Jang J, Ha D-H, Won Kim S, Rhie J-W, Shim J-H et al (2014) Printing three-dimensional tissue analogues with decellularized extracellular matrix bioink. Nat Commun 5(1):3935

133. Dzobo K, Motaung KSCM, Adesida A (2019) Recent trends in decellularized extracellular matrix bioinks for 3D printing: an updated review. Int J Mol Sci 20(18):4628

134. Kabirian F, Mozafari M (2020) Decellularized ECM-derived bioinks: prospects for the future. Methods 171:108-118

135. Iop L, Dal Sasso E, Menabò R, Di Lisa F, Gerosa G (2017) The rapidly evolving concept of whole heart engineering. Stem Cells Int 2017:8920940
136. Palmese LL, Thapa RK, Sullivan MO, Kiick KL (2019) Hybrid hydrogels for biomedical applications. Curr Opin Chem Eng 24:143-157

137. Prince E, Kumacheva E (2019) Design and applications of manmade biomimetic fibrillar hydrogels. Nat Rev Mater 4(2):99-115

138. Green JJ, Elisseeff JH (2016) Mimicking biological functionality with polymers for biomedical applications. Nature 540(7633):386-394

139. Derakhshanfar S, Mbeleck R, Xu K, Zhang X, Zhong W, Xing $M(2018) 3 D$ bioprinting for biomedical devices and tissue engineering: a review of recent trends and advances. Bioactive Mater 3(2):144-156

140. Wu Y, Kennedy P, Bonazza N, Yu Y, Dhawan A, Ozbolat I (2018) Three-dimensional bioprinting of articular cartilage: a systematic review. Cartilage 1947603518809410

141. Lim KS, Levato R, Costa PF, Castilho MD, Alcala-Orozco CR, van Dorenmalen KMA et al (2018) Bio-resin for high resolution lithography-based biofabrication of complex cell-laden constructs. Biofabrication 10(3):034101

142. Bernal PN, Delrot P, Loterie D, Li Y, Malda J, Moser C et al (2019) Volumetric bioprinting of complex living-tissue constructs within seconds. Adv Mater. https://doi.org/10.1002/ adma.201904209

143. Grigoryan B, Paulsen SJ, Corbett DC, Sazer DW, Fortin CL, Zaita AJ et al (2019) Multivascular networks and functional intravascular topologies within biocompatible hydrogels. Science 364(6439): 458

144. Pereira RF, Bártolo PJ (2015) 3D bioprinting of photocrosslinkable hydrogel constructs. J Appl Polym Sci 132(48)

145. Hospodiuk M, Dey M, Sosnoski D, Ozbolat IT (2017) The bioink: a comprehensive review on bioprintable materials. Biotechnol Adv 35(2):217-239

146. Gungor-Ozkerim PS, Inci I, Zhang YS, Khademhosseini A, Dokmeci MR (2018) Bioinks for 3D bioprinting: an overview. Biomater Sci 6(5):915-946. https://doi.org/10.1039/C7BM0 0765E

147. Paxton N, Smolan W, Böck T, Melchels F, Groll J, Jungst T (2017) Proposal to assess printability of bioinks for extrusionbased bioprinting and evaluation of rheological properties governing bioprintability. Biofabrication 9(4):044107

148. Hu W, Wang Z, Xiao Y, Zhang S, Wang J (2019) Advances in crosslinking strategies of biomedical hydrogels. Biomater Sci 7(3):843-855

149. Gao T, Gillispie GJ, Copus JS, Pr AK, Seol Y-J, Atala A et al (2018) Optimization of gelatin-alginate composite bioink printability using rheological parameters: a systematic approach. Biofabrication 10(3):034106

150. Ribeiro A, Blokzij1 MM, Levato R, Visser CW, Castilho M, Hennink WE et al (2017) Assessing bioink shape fidelity to aid material development in 3D bioprinting. Biofabrication 10(1):14102

151. Pereira RF, Sousa A, Barrias CC, Bártolo PJ, Granja PL (2018) A single-component hydrogel bioink for bioprinting of bioengineered 3D constructs for dermal tissue engineering. Mater Horizons 5(6):1100-1111

152. Malda J, Visser J, Melchels FP, Jüngst T, Hennink WE, Dhert WJA et al (2013) 25th anniversary article: engineering hydrogels for biofabrication. Adv Mater 25(36):5011-5028

153. Bertassoni LE, Cardoso JC, Manoharan V, Cristino AL, Bhise NS, Araujo WA et al (2014) Direct-write bioprinting of cell-laden methacrylated gelatin hydrogels. Biofabrication 6(2):024105

154. Nair K, Gandhi M, Khalil S, Yan KC, Marcolongo M, Barbee K et al (2009) Characterization of cell viability during bioprinting processes. Biotechnol J 4(8): 1168-1177

155. He Y, Yang F, Zhao H, Gao Q, Xia B, Fu J (2016) Research on the printability of hydrogels in 3D bioprinting. Sci Rep 6:29977 
156. Zou X, Kui X, Zhang R, Zhang Y, Wang X, Wu Q et al (2017) Viscoelasticity and structures in chemically and physically dual-cross-linked hydrogels: insights from rheology and proton multiple-quantum NMR spectroscopy. Macromolecules 50(23):9340-9352

157. Chimene D, Lennox KK, Kaunas RR, Gaharwar AK (2016) Advanced bioinks for 3D printing: a materials science perspective. Ann Biomed Eng 44(6):2090-2102

158. Levett PA, Melchels FPW, Schrobback K, Hutmacher DW, Malda J, Klein TJ (2014) A biomimetic extracellular matrix for cartilage tissue engineering centered on photocurable gelatin, hyaluronic acid and chondroitin sulfate. Acta Biomater 10(1):214-223

159. Kang H-W, Lee SJ, Ko IK, Kengla C, Yoo JJ, Atala A (2016) A $3 \mathrm{D}$ bioprinting system to produce human-scale tissue constructs with structural integrity. Nat Biotechnol 34(3):312-319

160. Kwon H, Paschos NK, Hu JC, Athanasiou K (2016) Articular cartilage tissue engineering: the role of signaling molecules. Cell Mol Life Sci 73(6):1173-1194

161. Fortier LA, Barker JU, Strauss EJ, McCarrel TM, Cole BJ (2011) The role of growth factors in cartilage repair. Clin Orthop Relat Res 469(10):2706-2715

162. Koons GL, Mikos AG (2019) Progress in three-dimensional printing with growth factors. J Control Release 295:50-59

163. Demoor M, Ollitrault D, Gomez-Leduc T, Bouyoucef M, Hervieu $\mathrm{M}$, Fabre $\mathrm{H}$ et al (2014) Cartilage tissue engineering: Molecular control of chondrocyte differentiation for proper cartilage matrix reconstruction. Biochimica et Biophysica Acta (BBA) 1840(8):2414-2440

164. Danišovič L', Varga I, Polák Š (2012) Growth factors and chondrogenic differentiation of mesenchymal stem cells. Tissue Cell 44(2):69-73

165. Patel JM, Saleh KS, Burdick JA, Mauck RL (2019) Bioactive factors for cartilage repair and regeneration: improving delivery, retention, and activity. Acta Biomater 93:222-238

166. Ahn J, Kim SA, Kim KW, Oh JH, Kim SJ (2019) Optimization of TGF- $\beta 1$-transduced chondrocytes for cartilage regeneration in a 3D printed knee joint model. PLoS ONE 14(5):e0217601

167. Diao H, Wang J, Shen C, Xia S, Guo T, Dong L et al (2009) Improved cartilage regeneration utilizing mesenchymal stem cells in TGF-beta1 gene-activated scaffolds. Tissue Eng Part A 15(9):2687-2698

168. Wei FY, Lee JK, Wei L, Qu F, Zhang JZ (2017) Correlation of insulin-like growth factor 1 and osteoarthritic cartilage degradation: a spontaneous osteoarthritis in guinea-pig. Eur Rev Med Pharmacol Sci 21(20):4493-4500

169. Moncada-Saucedo NK, Marino-Martinez IA, Lara-Arias J, Romero-Diaz VJ, Camacho A, Valdes-Franco JA et al (2019) A bioactive cartilage graft of IGF1-transduced adipose mesenchymal stem cells embedded in an alginate/bovine cartilage matrix tridimensional scaffold. Stem Cells Int 2019:9792369

170. Ertan AB, Yılgor P, Bayyurt B, Çalıkoğlu AC, Kaspar Ç, Kök FN et al (2013) Effect of double growth factor release on cartilage tissue engineering. J Tissue Eng Regen Med 7(2):149-160

171. Zykwinska A, Marquis M, Godin M, Marchand L, Sinquin C, Garnier C et al (2019) Microcarriers based on glycosaminoglycan-like marine exopolysaccharide for TGF- $\beta 1$ long-term protection. Marine Drug 17(1):65

172. Moncada-Saucedo NK, Marino-Martínez IA, Lara-Arias J, Romero-Díaz VJ, Camacho A, Valdés-Franco J, et al (2019) A bioactive cartilage graft of IGF1-transduced adipose mesenchymal stem cells embedded in an alginate/bovine cartilage matrix tridimensional scaffold. 2019

173. Fahy N, Alini M, Stoddart MJ (2018) Mechanical stimulation of mesenchymal stem cells: Implications for cartilage tissue engineering. J Orthop Res 36(1):52-63
174. Grad S, Eglin D, Alini M, Stoddart MJ (2011) Physical stimulation of chondrogenic cells in vitro: a review. Clin Orthop Relat Res 469(10):2764-2772. https://doi.org/10.1007/s1199 9-011-1819-9

175. Athanasiou KA, Responte DJ, Brown WE, Hu JC (2015) Harnessing biomechanics to develop cartilage regeneration strategies. J Biomech Eng 137(2)

176. Salinas EY, Hu JC, Athanasiou K (2018) A guide for using mechanical stimulation to enhance tissue-engineered articular cartilage properties. Tissue Eng Part B 24(5):345-358

177. Panadero JA, Lanceros-Mendez S, Ribelles JLG (2016) Differentiation of mesenchymal stem cells for cartilage tissue engineering: Individual and synergetic effects of three-dimensional environment and mechanical loading. Acta Biomater 33:1-12. https://doi.org/10.1016/j.actbio.2016.01.037

178. Osborne AC, Lamb KJ, Lewthwaite JC, Dowthwaite GP, Pitsillides AA (2002) Short-term rigid and flaccid paralyses diminish growth of embryonic chick limbs and abrogate joint cavity formation but differentially preserve pre-cavitated joints. J Musculoskelet Neuronal Interact 2(5):448-456

179. Roddy KA, Prendergast PJ, Murphy P (2011) Mechanical influences on morphogenesis of the knee joint revealed through morphological, molecular and computational analysis of immobilised embryos. PLoS ONE 6(2):e17526-e

180. Fang J, Hall BK (1995) Differential expression of neural cell adhesion molecule (NCAM) during osteogenesis and secondary chondrogenesis in the embryonic chick. Int J Dev Biol 39(3):519-528

181. Zhao J, Griffin M, Cai J, Li S, Bulter PEM, Kalaskar DM (2016) Bioreactors for tissue engineering: an update. Biochem Eng J 109:268-281

182. Li K, Zhang C, Qiu L, Gao L, Zhang X (2017) Advances in application of mechanical stimuli in bioreactors for cartilage tissue engineering. Tissue Eng Part B 23(4):399-411

183. Nigel M, Sandip H, Wasim SK (2012) The role of bioreactors in cartilage tissue engineering. Curr Stem Cell Res Ther 7(4):287-292

184. Meinert C, Schrobback K, Hutmacher DW, Klein TJ (2017) A novel bioreactor system for biaxial mechanical loading enhances the properties of tissue-engineered human cartilage. Sci Rep 7(1):16997

185. Schatti O, Grad S, Goldhahn J, Salzmann G, Li Z, Alini M et al (2011) A combination of shear and dynamic compression leads to mechanically induced chondrogenesis of human mesenchymal stem cells. Eur Cell Mater 22:214-225

186. Vainieri ML, Wahl D, Alini M, van Osch GJVM, Grad S (2018) Mechanically stimulated osteochondral organ culture for evaluation of biomaterials in cartilage repair studies. Acta Biomater $81: 256-266$

187. Lee JK, Huwe LW, Paschos N, Aryaei A, Gegg CA, Hu JC et al (2017) Tension stimulation drives tissue formation in scaffoldfree systems. Nat Mater 16:864

188. Vinardell T, Sheehy EJ, Buckley CT, Kelly DJ (2012) A comparison of the functionality and in vivo phenotypic stability of cartilaginous tissues engineered from different stem cell sources. Tissue Eng Part A 18(11-12):1161-1170

189. Pitsillides AA, Beier F (2011) Cartilage biology in osteoarthritis-lessons from developmental biology. Nat Rev Rheumatol 7(11):654-663

190. Mwale F, Yao G, Ouellet JA, Petit A, Antoniou J (2010) Effect of parathyroid hormone on type $\mathrm{X}$ and type II collagen expression in mesenchymal stem cells from osteoarthritic patients. Tissue Eng Part A 16(11):3449-3455

191. Kim Y-J, Kim H-J, Im G-I (2008) PTHrP promotes chondrogenesis and suppresses hypertrophy from both bone 
marrow-derived and adipose tissue-derived MSCs. Biochem Biophys Res Commun 373(1):104-108

192. Caron MMJ, Emans PJ, Cremers A, Surtel DAM, Coolsen MME, van Rhijn LW et al (2013) Hypertrophic differentiation during chondrogenic differentiation of progenitor cells is stimulated by BMP-2 but suppressed by BMP-7. Osteoarth Cartilage 21(4):604-613

193. Ikeda T, Kamekura S, Mabuchi A, Kou I, Seki S, Takato T et al (2004) The combination of SOX5, SOX6, and SOX9 (the SOX trio) provides signals sufficient for induction of permanent cartilage. Arthritis Rheum 50(11):3561-3573

194. Lengner CJ, Hassan MQ, Serra RW, Lepper C, van Wijnen AJ, Stein JL et al (2005) Nkx3.2-mediated repression of Runx 2 promotes chondrogenic differentiation. J Biol Chem 280(16): 15872-15879

195. van der Kraan PM (2019) The interaction between joint inflammation and cartilage repair. Tissue Eng Regenerat Med 16(4):327-334

196. Boehme KA, Rolauffs B (2018) Onset and progression of human osteoarthritis-Can growth factors, inflammatory cytokines, or differential miRNA expression concomitantly induce proliferation, ECM Degradation, and inflammation in articular cartilage? Int J Mol Sci 19(8):2282

197. Rainbow R, Ren W, Zeng L (2012) Inflammation and joint tissue interactions in OA: implications for potential therapeutic approaches. Arthritis 2012:741582

198. Goldring SR, Goldring MB (2004) The role of cytokines in cartilage matrix degeneration in osteoarthritis. Clin Orthop Relat Res 427:S27-S36

199. Chow YY, Chin K-Y (2020) The Role of inflammation in the pathogenesis of osteoarthritis. Mediators Inflamm 2020:8293921

200. Kapoor M, Martel-Pelletier J, Lajeunesse D, Pelletier J-P, Fahmi $\mathrm{H}$ (2011) Role of proinflammatory cytokines in the pathophysiology of osteoarthritis. Nat Rev Rheumatol 7(1):33-42

201. van den Bosch MHJ (2019) Inflammation in osteoarthritis: is it time to dampen the alarm(in) in this debilitating disease? Clin Exp Immunol 195(2):153-166

202. Wehling N, Palmer GD, Pilapil C, Liu F, Wells JW, Müller PE et al (2009) Interleukin-1 $\beta$ and tumor necrosis factor $\alpha$ inhibit chondrogenesis by human mesenchymal stem cells through

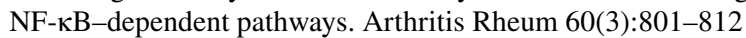

203. Heldens GTH, Blaney Davidson EN, Vitters EL, Schreurs BW, Piek E, van den Berg WB et al (2011) Catabolic factors and osteoarthritis-conditioned medium inhibit chondrogenesis of human mesenchymal stem cells. Tissue Eng Part A 18(1-2):45-54

204. Lai JH, Rogan H, Kajiyama G, Goodman SB, Smith RL, Maloney $\mathrm{W}$ et al (2014) Interaction between osteoarthritic chondrocytes and adipose-derived stem cells is dependent on cell distribution in three-dimension and transforming growth factor- $\beta 3$ induction. Tissue Eng Part A 21(5-6):992-1002

205. Andia I, Maffulli N (2013) Platelet-rich plasma for managing pain and inflammation in osteoarthritis. Nat Rev Rheumatol 9(12):721-730

206. Cook CS, Smith PA (2018) Clinical update: Why PRP should be your first choice for injection therapy in treating osteoarthritis of the knee. Curr Rev Musculoskelet Med 11(4):583-592

207. Gato-Calvo L, Magalhaes J, Ruiz-Romero C, Blanco FJ, Burguera EF (2019) Platelet-rich plasma in osteoarthritis treatment: review of current evidence. Ther Adv Chronic Dis 10:2040622319825567

208. Zhu Y, Yuan M, Meng HY, Wang AY, Guo QY, Wang Y et al (2013) Basic science and clinical application of platelet-rich plasma for cartilage defects and osteoarthritis: a review. Osteoarthr Cartilage 21(11):1627-1637
209. Utomo L, van Osch GJVM, Bayon Y, Verhaar JAN, BastiaansenJenniskens YM (2016) Guiding synovial inflammation by macrophage phenotype modulation: an in vitro study towards a therapy for osteoarthritis. Osteoarthr Cartilage 24(9):1629-1638

210. Hamasaki M, Terkawi MA, Onodera T, Homan K, Iwasaki N (2019) A novel cartilage fragments stimulation model revealed that macrophage inflammatory response causes an upregulation of catabolic factors of chondrocytes in vitro. Cartilage 1947603519828426.

211. Utomo L, Bastiaansen-Jenniskens YM, Verhaar JAN, van Osch GJVM (2016) Cartilage inflammation and degeneration is enhanced by pro-inflammatory (M1) macrophages in vitro, but not inhibited directly by anti-inflammatory (M2) macrophages. Osteoarthr Cartilage 24(12):2162-2170

212. Lolli A, Colella F, De Bari C, van Osch GJVM (2019) Targeting anti-chondrogenic factors for the stimulation of chondrogenesis: a new paradigm in cartilage repair. J Orthop Res 37(1):12-22

213. Ayerst BI, Merry CLR, Day AJ (2017) The good the bad and the ugly of glycosaminoglycans in tissue engineering applications. Pharmaceuticals 10(2):54

214. Koh RH, Jin Y, Kim J, Hwang NS (2020) Inflammation-modulating hydrogels for osteoarthritis cartilage tissue engineering. Cells 9(2):419

215. Khan IM, Gilbert SJ, Singhrao SK, Duance VC, Archer CW (2008) Cartilage integration: evaluation of the reasons for failure of integration during cartilage repair. A review. Eur Cell Mater 16:26-39

216. Arvayo AL, Wong IJ, Dragoo JL, Levenston ME (2018) Enhancing integration of articular cartilage grafts via photochemical bonding. J Orthop Res 36(9):2406-2415

217. Hunziker EB, Kapfinger E, Müller ME (1998) Removal of proteoglycans from the surface of defects in articular cartilage transiently enhances coverage by repair cells. J Bone Joint Surg Br Volume 80-B(1):144-150

218. Obradovic B, Martin I, Padera RF, Treppo S, Freed LE, VunjakNavakovic G (2001) Integration of engineered cartilage. J Orthop Res 19(6):1089-1097

219. Makris EA, MacBarb RF, Paschos NK, Hu JC, Athanasiou KA (2014) Combined use of chondroitinase-ABC, TGF$\beta 1$, and collagen crosslinking agent lysyl oxidase to engineer functional neotissues for fibrocartilage repair. Biomaterials 35(25):6787-6796

220. van de Breevaart BJ, ln der Maur CD, Bos PK, Feenstra L, Verhaar JAN, Weinans $\mathrm{H}$ et al (2004) Improved cartilage integration and interfacial strength after enzymatic treatment in a cartilage transplantation model. Arthritis Res Ther 6(5):R469

221. Athens AA, Makris EA, Hu JC (2013) Induced collagen crosslinks enhance cartilage integration. PLoS ONE 8(4):e60719

222. Vapniarsky N, Huwe LW, Arzi B, Houghton MK, Wong ME, Wilson JW et al (2018) Tissue engineering toward temporomandibular joint disc regeneration. Sci Trans Med 10(446):eaaq1802

223. Arzi B, DuRaine GD, Lee CA, Huey DJ, Borjesson DL, Murphy BG et al (2015) Cartilage immunoprivilege depends on donor source and lesion location. Acta Biomater 23:72-81

224. Evans CH, Ghivizzani SC, Robbins PD (2018) Arthritis gene therapy is becoming a reality. Nat Rev Rheumatol 14(7):381-382

225. Cucchiarini M, Madry H (2019) Biomaterial-guided delivery of gene vectors for targeted articular cartilage repair. Nat Rev Rheumatol 15(1):18-29

Publisher's Note Springer Nature remains neutral with regard to jurisdictional claims in published maps and institutional affiliations. 